\title{
Valores de geodiversidade aplicados a solos na bacia hidrográfica do rio Escuro, Ubatuba, SP, Brasil
}

\author{
Geodiversity values applied to soils in river Escuro drainage \\ basin, Ubatuba, SP, Brazil
}

\section{Valores de geodiversidad aplicados a suelos en la cuenca del río Escuro, Ubatuba, SP, Brasil}

\author{
Aline Muniz Rodrigues \\ https:/ / orcid.org/0000-0002-4972-681X \\ alinemrodrigues@live.com \\ Universidade Federal do Rio de Janeiro, UFRJ, Rio de Janeiro, RJ \\ Leonardo dos Santos Pereira \\ https:/ / orcid.org/0000-0002-8389-9933 \\ leospgeo@gmail.com \\ Universidade Federal do Rio de Janeiro, UFRJ, Rio de Janeiro, RJ \\ Maria do Carmo Oliveira Jorge \\ https:/ / orcid.org/0000-0002-5375-2172 \\ orofila@gmail.com \\ Universidade Federal do Rio de Janeiro, UFRJ, Rio de Janeiro, RJ \\ Antonio José Teixeira Guerra \\ https:// orcid.org/0000-0003-2562-316X \\ antoniotguerra@gmail.com
}

Universidade Federal do Rio de Janeiro, UFRJ, Rio de Janeiro, RJ

Resumo: O solo pode ser considerado um elemento da geodiversidade dotado de diferentes valores, no entanto sua significância é frequentemente subestimada. Nesta perspectiva, este estudo pretende aplicar aos solos o sistema de valoração da geodiversidade baseado nos serviços ecossistêmicos de suporte, provisão, regulação, cultural e conhecimento, desenvolvido por Gray (2013). O estudo foi conduzido no Sítio PROMATA, na bacia hidrográfica do rio Escuro, em Ubatuba, SP. Os resultados das análises físicas e químicas remetem à boa estrutura do solo, com médias de densidade inferiores a $0,8 \mathrm{~g} / \mathrm{cm}^{3}$ e a porosidade total com médias superiores a $70 \%$, condição importante para que o solo realize suas funções. Portanto, os solos desempenham variados serviços ecossistêmicos, indispensáveis para a realização das atividades humanas e o funcionamento equilibrado dos sistemas ambientais.

Palavras-chave: conservação dos solos, geoconservação, sistema de valoração. 


\begin{abstract}
Soil can be considered an element of geodiversity with different values; however, its significance is often underestimated. In this perspective, this research aims to apply to the soils the geodiversity valuation system based on ecosystem support, provision, regulation, cultural and knowledge services, developed by Gray (2013). The research was conducted at the PROMATA Farm, in the river Escuro drainage basin, Ubatuba Municipality, São Paulo State. Results of physical and chemical analyzes refer to the good soil structure, soil density average less than $0.8 \mathrm{~g} / \mathrm{cm}^{3}$, and the total porosity average over $70 \%$, it is an important condition for the soil to perform its functions. Therefore, soils perform several ecosystem services, essential for the accomplishment of human activities and the balanced operation of the environmental systems.
\end{abstract}

Keywords: soil conservation, geoconservation, system of valuation.

Resumen: El suelo puede considerarse un elemento de geodiversidad con diferentes valores, sin embargo, su importancia a menudo se subestima. En esta perspectiva, este estudio pretende aplicar a los suelos el sistema de valoración de la geodiversidad basado en el sustento, provisión, regulación, servicios culturales y de conocimiento de los ecosistemas, desarrollado por Gray (2013). El estudio se realizó en el Sítio PROMATA, en la cuenca hidrográfica del río Escuro, en Ubatuba, SP. Los resultados de los análisis físicos y químicos se refieren a la buena estructura del suelo, su densidad promedio es menor a $0,8 \mathrm{~g} / \mathrm{cm}^{3}$ y la porosidad total promedio superior al $70 \%$, condición importante para que el suelo realice sus funciones.Por lo tanto, los suelos realizan una variedad de servicios ecosistémicos, que son indispensables para el desempeño de las actividades humanas y el funcionamiento equilibrado de los sistemas ambientales.

Palabras clave: conservación del suelo, geoconservación, sistema de valoración.

\title{
INTRODUÇÃO
}

Estudos que abrangem a temática da geodiversidade têm adquirido mais visibilidade no campo das Geociências e, desta forma, têm contribuído para a conservação dos elementos abióticos que, alicerçados aos elementos bióticos, formam o meio natural, complexo e diverso. A geodiversidade está relacionada, sobretudo, ao conjunto formado pelos elementos geológicos e geomorfológicos, contudo podendo estar associado aos hidrológicos e pedológicos, além de fenômenos e processos que originam e transformam a natureza. Possui diferentes valores para a sociedade e permite obter conhecimento sobre a geosfera e sua interação com os demais sistemas terrestres (Brilha, 2016).

Elementos bióticos e abióticos estão expostos à degradação, colocando em risco relevantes meios de se compreender melhor o passado e evolução do nosso planeta, uma vez que as rochas, os minerais, os solos, os fósseis, as formas do relevo, os processos naturais, detêm informações imprescindíveis para o avanço do conhecimento científico. Levando tal perspectiva em consideração, Mochiutti, Guimarães e Melo (2011) ressaltam que a necessidade de conservação da natureza é um fato concreto, sendo o processo de atribuição de valores uma maneira de promover a proteção, tanto da biodiversidade, quanto da geodiversidade. Assim, a definição de valores constitui parte fundamental nas estratégias de geoconservação, hierarquizando locais de maior necessidade de proteção (Brilha, 2016).

Os elementos da geodiversidade são dotados de valores, sendo comum a todos os elementos o valor intrínseco, visto que são importantes pelo simples fato de existirem, 
independentemente da sua utilidade ou não para o homem (Gray, 2013). Contudo, quando se atenta para o solo, especificamente, constata-se que o mesmo ainda é pouco abordado nas pesquisas, principalmente nacionais, não somente em relação à divulgação dos seus diferentes valores para a sociedade, mas também nota-se certa falta de atenção em relação ao seu papel como elemento importante da geodiversidade, quando se compara aos demais elementos como rochas e fósseis, por exemplo, comumente abordados em estudos sobre a geodiversidade.

Na acepção de Conway (2010), o solo corresponde um recurso natural que apresenta valores variados para a sociedade, possuindo papel indispensável para o adequado funcionamento dos sistemas ambientais. Por sua vez, Fontes e Muggler (1999) também salientam a relevância dos solos, porém relatam que sua significância é frequentemente despercebida e subestimada, sendo, por isso, primordial a compreensão de que o solo é parte essencial do meio ambiente.

Portanto, a justificativa principal para a realização desta pesquisa está relacionada à pouca atenção atribuída aos solos como elemento da geodiversidade, o que tende a contribuir para o aumento dos problemas ambientais ligados à degradação deste elemento abiótico. A falta de informação no que diz respeito às suas potencialidades e limitações colabora com sua degradação, uma vez que as pessoas, em sua maioria, apresentam atitude de pouca consciência e sensibilidade em relação aos solos (Muggler, Pinto Sobrinho \& Machado, 2006).

Nesta perspectiva, a pesquisa possui como objetivo utilizar o sistema de valoração da geodiversidade, baseado nos serviços ecossistêmicos, desenvolvido por Gray (2013), para o enquadramento específico dos solos, buscando, assim, destacar a importância e a necessidade de sua conservação, tendo como área de estudo o Sítio PROMATA (Associação de Moradores Para a Recuperação e Preservação da Mata Atlântica), localizado na bacia hidrográfica do rio Escuro, Ubatuba (SP).

Ressalta-se que os serviços ecossistêmicos, entendidos como um conjunto de benefícios tangíveis, como alimentos, e intangíveis, como regulação do clima, resultante da dinâmica da natureza e que podem ser aproveitados para o bem-estar do homem, consistem em um conceito importante aplicado na valoração qualitativa da diversidade natural, possibilitando ações de conservação e preservação do meio ambiente. Sendo assim, a valoração baseada nos serviços ecossistêmicos corresponde a uma valoração qualitativa dos aspectos abióticos da natureza, focada na conservação, por meio da difusão de conhecimentos ligados às Geociências (Andrade \& Romeiro, 2009; Silva, Mansur \& Nascimento, 2018).

Por sua vez, a atribuição de valores para a geodiversidade pode ser compreendida como "uma forma de descrever a contribuição da natureza para a qualidade de vida no planeta, provendo uma boa relação entre os estudos da geodiversidade com os da biodiversidade" (Silva \& Nascimento, 2016, p. 341). Botelho, Pelech e Souza (2018, p.3) também salientam que

O valor da geodiversidade também está apoiado nas suas múltiplas funções e na influência sobre a vida das pessoas e sobre a própria Natureza, em ambientes naturais e construídos. Em outras palavras, os elementos da geodiversidade constituem capital natural e realizam serviços ecossistêmicos essenciais à vida na Terra, ao desenvolvimento das atividades econômicas (desde as mais artesanais até as que se utilizam de 
tecnologia de ponta) e a evolução das sociedades. E seu valor pode estar atrelado a diferentes escalas, excludentes ou não: internacional, nacional, regional e local.

\section{ÁREA DE ESTUDO}

O Sítio PROMATA localiza-se na bacia hidrográfica do rio Escuro ${ }^{1}$, no bairro do Corcovado, município de Ubatuba, litoral norte do estado de São Paulo, com acesso a partir da Praia Dura, na entrada para o Pico do Corcovado (Estrada do Corcovado - 13513, Rod. Gov. Mário Covas, São Paulo) (Fig. 1). Esta propriedade privada possui área de 142,72 ha, com pouco mais de sua metade localizada acima da cota altimétrica dos 100 metros do nível do mar, no Parque Estadual da Serra do Mar. Seu uso está voltado para o desenvolvimento de atividades ligadas à educação, observação, contemplação e proteção das áreas naturais.

A PROMATA é uma associação de base comunitária com o objetivo da promoção de atividades sustentáveis para a garantia da identidade cultural, o desenvolvimento socioeconômico e a preservação do meio ambiente. Tem trabalhado em parceria com o Parque Estadual da Serra do Mar, no desenvolvimento de atividades de educação ambiental voltadas para a conservação da natureza.

Figura 1: Localização do Sítio PROMATA, Ubatuba, SP, com destaque para a casa sede (A); entrada para o sítio, com ênfase na vegetação de Mata Atlântica (B); presença de cachoeira (C); presença de painel interpretativo voltado para o entendimento da geodiversidade da área (D).

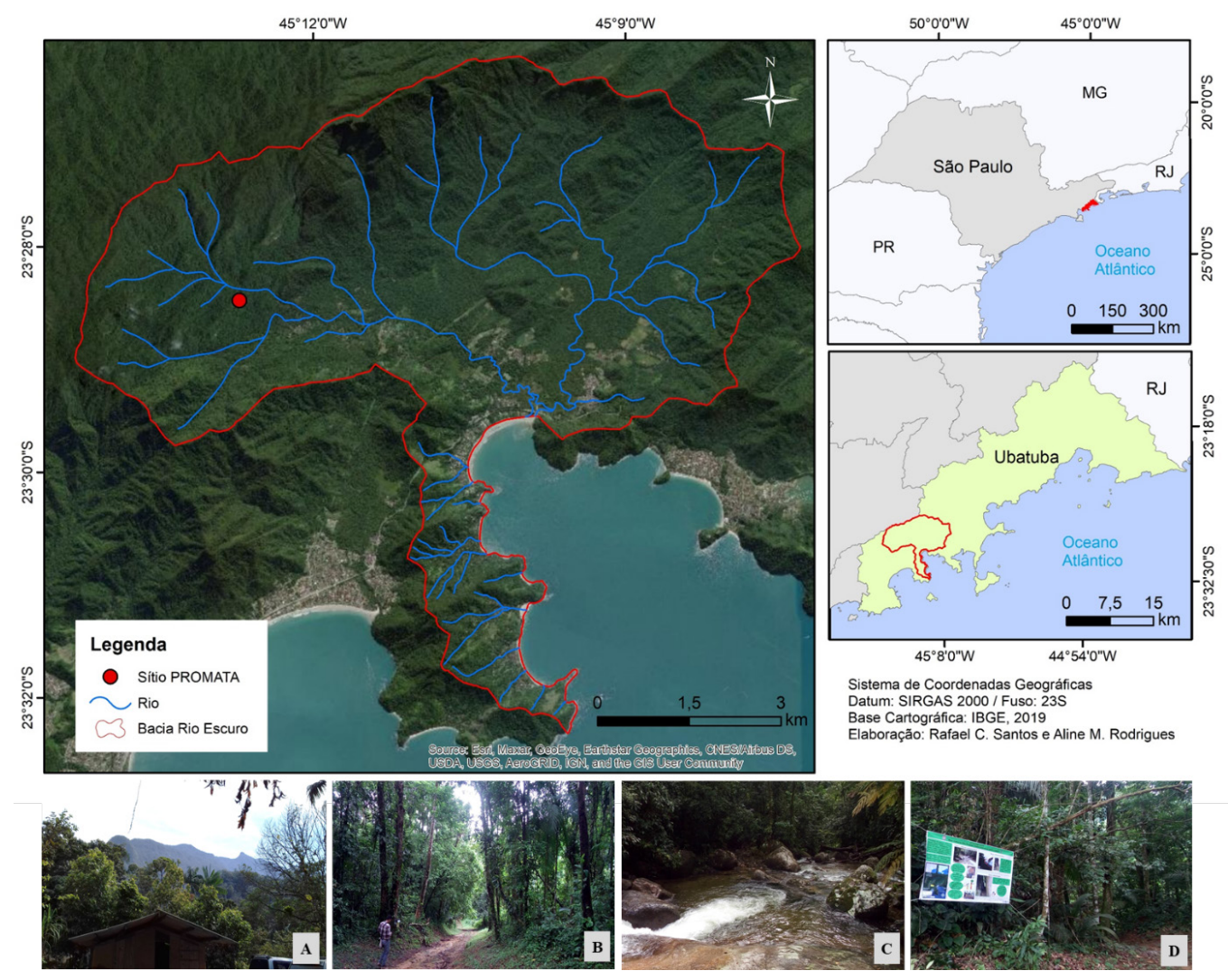

1 O recorte da bacia foi realizado de acordo com o Relatório II do Plano de Bacias Hidrográficas do Litoral Norte de São Paulo, UGRHI 03, disponibilizado pelo Comitê de Bacias Hidrográficas do Litoral Norte (CBH-LN, 2017). 
O município de Ubatuba possui 80\% de seu território localizado no Parque Estadual da Serra do Mar, onde a Mata Atlântica encontra-se em bom estado de conservação. A Mata Atlântica, denominada de Floresta Ombrófila Densa ou Floresta Atlântica de Encosta, possui grande relevância, apresentando diversidade florística, espécies endêmicas e ameaçadas de extinção, ambiente interno sombreado, exercendo papel fundamental para o equilíbrio ambiental (Santos, 2004; Ministério de Meio Ambiente, 2019).

O clima é caracterizado como tropical litorâneo úmido ou tropical atlântico, com temperatura média anual de $21^{\circ} \mathrm{C}$. A temperatura média máxima chega a $27^{\circ} \mathrm{C}$ e a média mínima, de $15^{\circ} \mathrm{C}$. Predominam as massas tropicais, com atuação de frentes frias, as quais conjugadas com as características morfológicas e altimétricas da Serra do Mar são responsáveis por grande parte dos eventos pluviais extremos. Nesse sentido, pode-se observar o predomínio das chuvas do tipo orográficas, de pequena intensidade e longa duração (Sant' Anna Neto, 1990).

Segundo Pereira (2019), os meses mais úmidos em Ubatuba são janeiro, março e dezembro, meses que apresentaram as maiores médias mensais de 2009 a 2018, de acordo com a leitura diária de um pluviômetro instalado no bairro Araribá. Maio a setembro foram caracterizados como os meses mais secos, com as menores médias mensais no período de dez anos analisados (Fig. 2).

Figura 2: Média mensal de 10 anos de chuva (2009 até 2018).

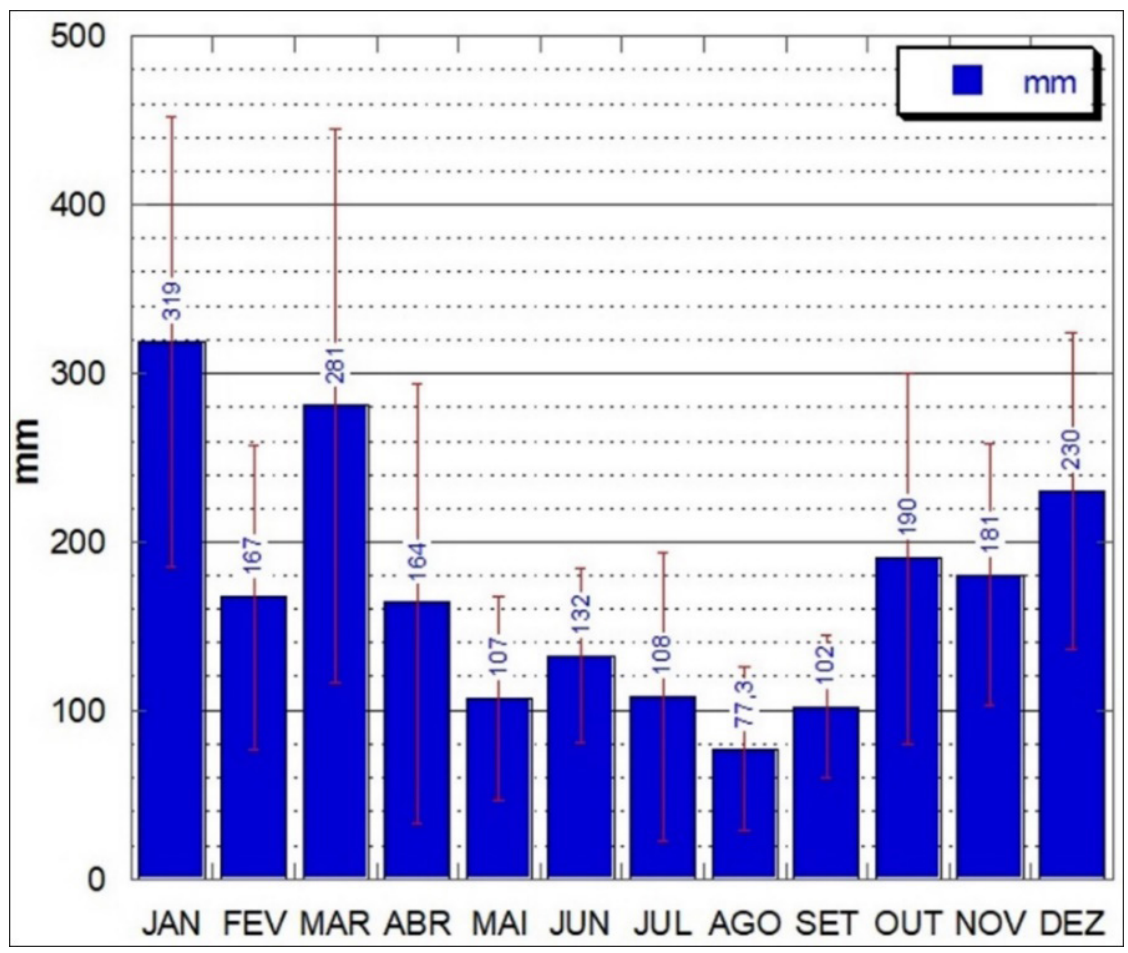

Fonte: Pereira (2019).

Do ponto de vista geológico, o município de Ubatuba está localizado em área cujo domínio pertence às rochas do embasamento cristalino agrupadas no Complexo Costeiro, estruturando a Serra do Mar. Os principais tipos de rochas encontradas são granitos e gnaisses. 
O Complexo Costeiro representa um dos terrenos que convergiram durante a aglutinação do Supercontinente Gondwana, no Neoproterozoico/Cambriano (Tupinambá et al., 2007).

Destaca-se o relevo montanhoso da Serra do Mar, como também a planície litorânea, que apresenta uma linha de costa bastante recortada. Cruz (1990) ressalta que no litoral norte de São Paulo, a Serra do Mar apresenta dois compartimentos diferentes, um a montante e o outro a jusante. O primeiro compartimento, localizado a montante da Serra do Mar, é caracterizado pela presença de vertentes escarpadas, com segmentos retilíneos alongados e declivosos, entalhadas por vales e anfiteatros de acentuadas amplitudes topográficas. A jusante tem-se o segundo compartimento, formado por vertentes escarpadas degradadas ou rebaixadas em distintos níveis topográficos, localizadas nas médias e baixas encostas. A planície litorânea, por sua vez, apresenta relevo plano originado por processos litorâneos e corresponde à área drenada diretamente para o mar, num sistema de drenagem de baixa densidade com padrão meandrante. Contudo, também podem ser encontrados padrões anastomosados, como nos mangues, sujeitos à ação das marés (Ponçano et al., 1981).

Conforme a Figura 3, na área predominam Cambissolos, associados às escarpas e aos colúvios das médias e baixas vertentes. Neossolos Litólicos podem ser encontrados em relevos de alta declividade, enquanto Neossolos Quartzarênicos ocorrem nas áreas de praia. Podem ser encontrados ainda Gleissolos nas áreas de mangue e nas planícies fluviais, e Espodossolos em relevo plano, na parte frontal da planície litorânea (Rossi, 1999; Fierz, 2008).

Figura 3: Mapa pedológico do município de Ubatuba, SP, com delimitação da bacia do rio Escuro.

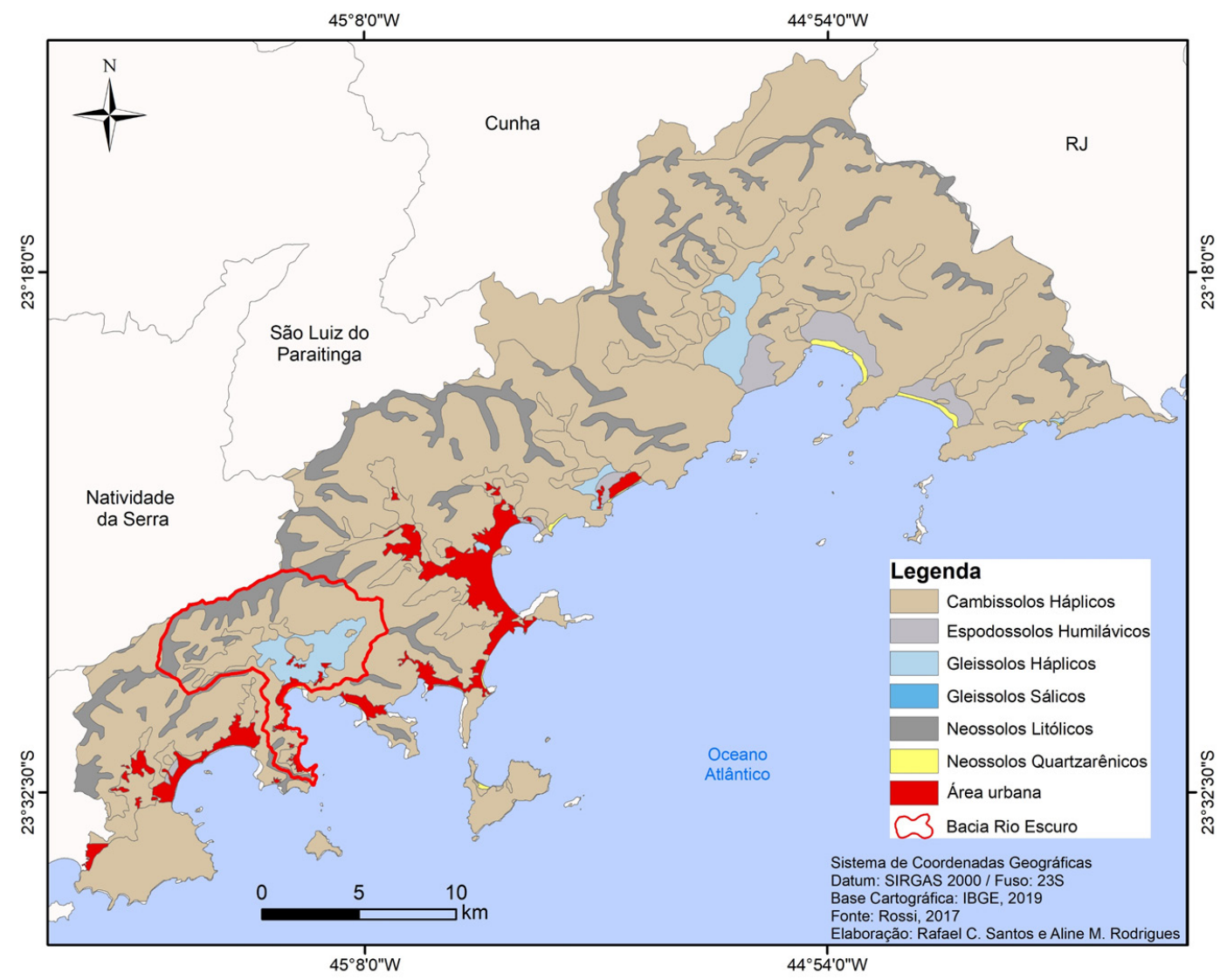

Fonte: Rossi (2017). 
Fierz (2008) discute sobre as principais características dos Cambissolos da área, destacando que os mesmos são

Moderadamente drenados e pouco profundos, área de ocorrência associada ao relevo ondulado e escarpado do planalto nos diferentes subcompartimentos sobre gnaisse e espalhado em toda a escarpa sobre granito; também encontrados nas planícies fluviais dos principais cursos de água e cones de dejeção das médias e baixas vertentes da escarpa, em vegetação de porte médio a alto, homogênea quanto ao dossel; possui textura média (Fierz, 2008, p. 200).

A espessura dos solos nas áreas de vertente é pequena, aprofunda-se nas áreas de crista dos espigões e nos fundos de vale, estando relacionada aos processos de movimentos de massa, à inclinação da vertente, à estrutura da rocha mãe e à pluviosidade da área. Encontra-se, comumente, logo abaixo da camada de serrapilheira o solo superficial. Abaixo deste ocorrem os saprolitos, produto de alteração do embasamento rochoso. Por meio de processos de escorregamento, rastejo e erosão, formam-se solos localizados nas áreas mais baixas das vertentes, os colúvios (Gobbi \& Ladeira, 2011).

Sobre este aspecto, Rossi (1999) salienta que os colúvios estão situados no sopé da Serra do Mar, formados por material decomposto oriundo de suas vertentes, estando associados a solos mais profundos, como Latossolos. Conclui também que, devido às altas declividades, em sua maioria, os solos são pouco espessos, enquanto que na planície litorânea o nível freático possui influência direta nas características dos solos.

O município de Ubatuba, assim como os demais municípios que compõem o Litoral Norte de São Paulo (Caraguatatuba, São Sebastião e Ilhabela), apresenta grande riqueza em geodiversidade. Além da fauna e flora exuberantes, há potencial geoturístico em afloramentos rochosos em distintos estágios evolutivos, sendo meio de compreensão da origem e evolução geológica desta área. Diversas formas geomorfológicas, processos pedogenéticos, entre outros, fazem parte do conjunto da geodiversidade, além de monumentos e construções que contêm importância para a geodiversidade, com elevado valor científico, didático e turístico, como demonstram estudos realizados por Santos (2014), Mucivuna (2016), Arruda, Garcia e Del Lama (2017), Garcia, Del Lama, Bourotte, Mazoca, Bacci e Santos (2017), Jorge (2017) e Mazzucato (2017).

\section{MATERIAIS E MÉTODOS}

A metodologia da pesquisa foi pautada em etapas de gabinete e campo. A etapa de gabinete foi direcionada para a realização da pesquisa bibliográfica, objetivando apresentar o sistema de valoração para a geodiversidade atualizado por Gray (2013) (Fig. 4). Posteriormente, tal sistema foi utilizado para ressaltar os valores dos solos baseados nos serviços ecossistêmicos de suporte, provisão, regulação, cultural e conhecimento. 
Figura 4: Sistema de valoração para a geodiversidade com base nos serviços ecossistêmicos, segundo Gray (2013).

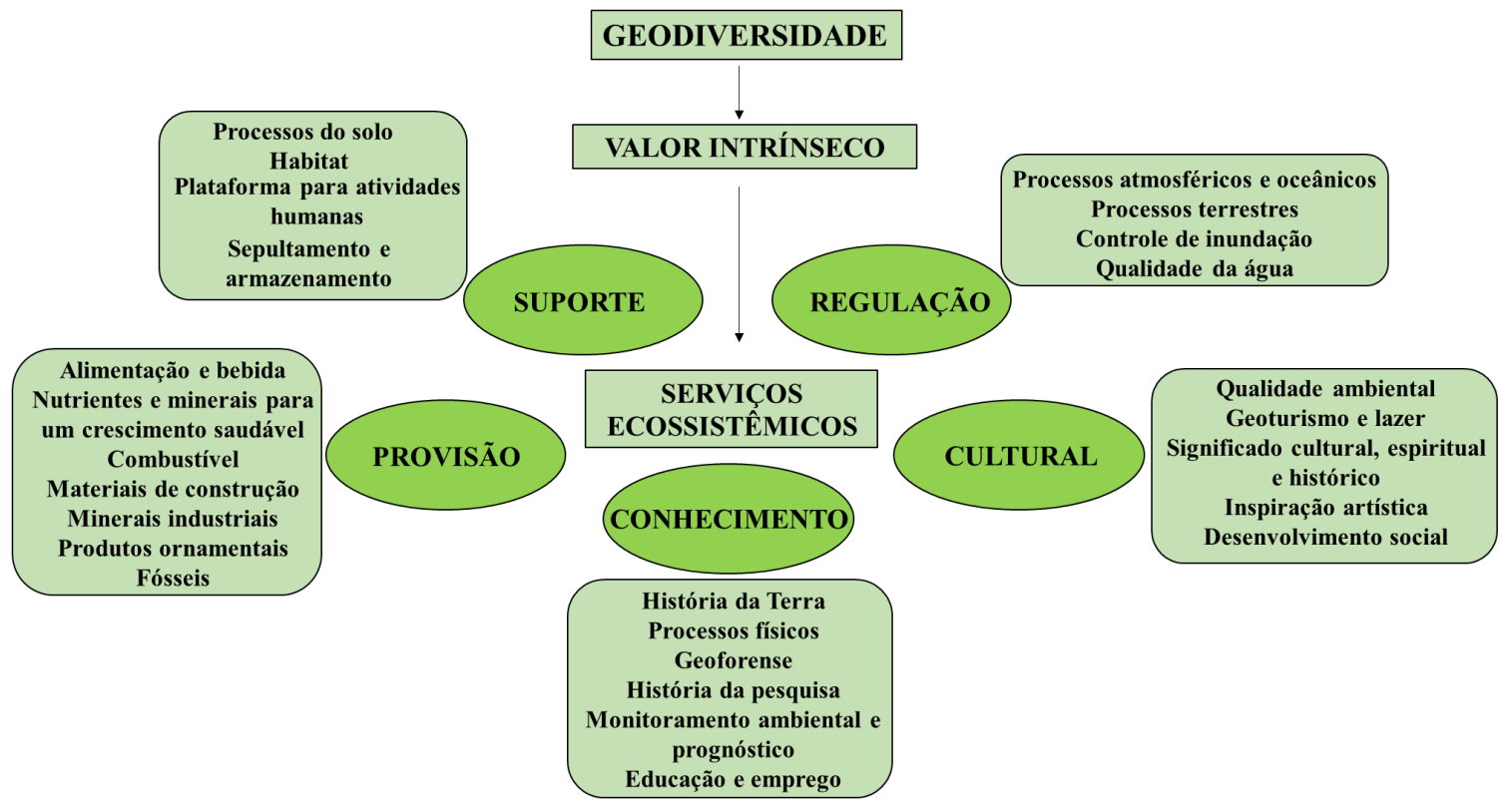

Para avaliar a qualidade do solo da área, uma vez que ela está relacionada ao adequado funcionamento dos ecossistemas naturais, estando também diretamente vinculada aos serviços ambientais provenientes do solo (Karlen, Mausbach, Doran, Cline, Harris \& Schuman, 1997; Vezzani \& Mielniczuk, 2011; Vezzani, 2015), foram coletadas em setembro de 2017 e fevereiro de 2018 amostras em profundidade de 0-10 cm, em triplicata, em quatro pontos, totalizando 12 amostras, por meio da utilização de anéis de Kopeck de $100 \mathrm{~cm}^{3}$. Coletas superficiais (até $10 \mathrm{~cm}$ ) visam amostrar solos com maior impacto do pisoteio que podem apresentar mudanças rápidas e significativas, como redução da porosidade total e aumento da densidade do solo, favorecendo o escoamento superficial (Guerra, 2009; Jorge, Guerra \& Fullen, 2016). As amostras foram coletadas em poucos pontos aleatórios e, por vezes, próximos, em decorrência da necessidade de locais com condições adequadas, com ausência de rochas e raízes grandes.

Foram determinadas densidade do solo e porosidade total (método do anel volumétrico), granulometria (método da pipeta), $\mathrm{pH}$ (princípio da medição do potencial eletronicamente por meio de eletrodo combinado imerso em suspensão solo/água) e teor de matéria orgânica (princípio da oxidação da matéria orgânica por via úmida, com dicromato de potássio em meio sulfúrico), segundo a metodologia da Empresa Brasileira de Pesquisa Agropecuária (EMBRAPA, 2011). A estabilidade de agregados em água, por sua vez, foi determinada através do Yoder (Yoder, 1936), de modo a calcular o Diâmetro Médio Ponderado (DMP), Diâmetro Médio Geométrico (DMG) e Índice de Estabilidade de Agregados (IEA), de acordo com Castro Filho, Muzilli e Podanoschi (1998).

Com o objetivo de realizar uma caracterização mais completa do solo, foram coletadas amostras em perfil, também em triplicata, em diferentes profundidades, de acordo com sua diferenciação morfológica (Fig. 5; Quadro 1) segundo o Manual Técnico de Pedologia (Instituto Brasileiro de Geografia e Estatística [IBGE], 2015). 
Figura 5: Coletas de amostras de solo de 0-10 cm (A) e em perfil (B).
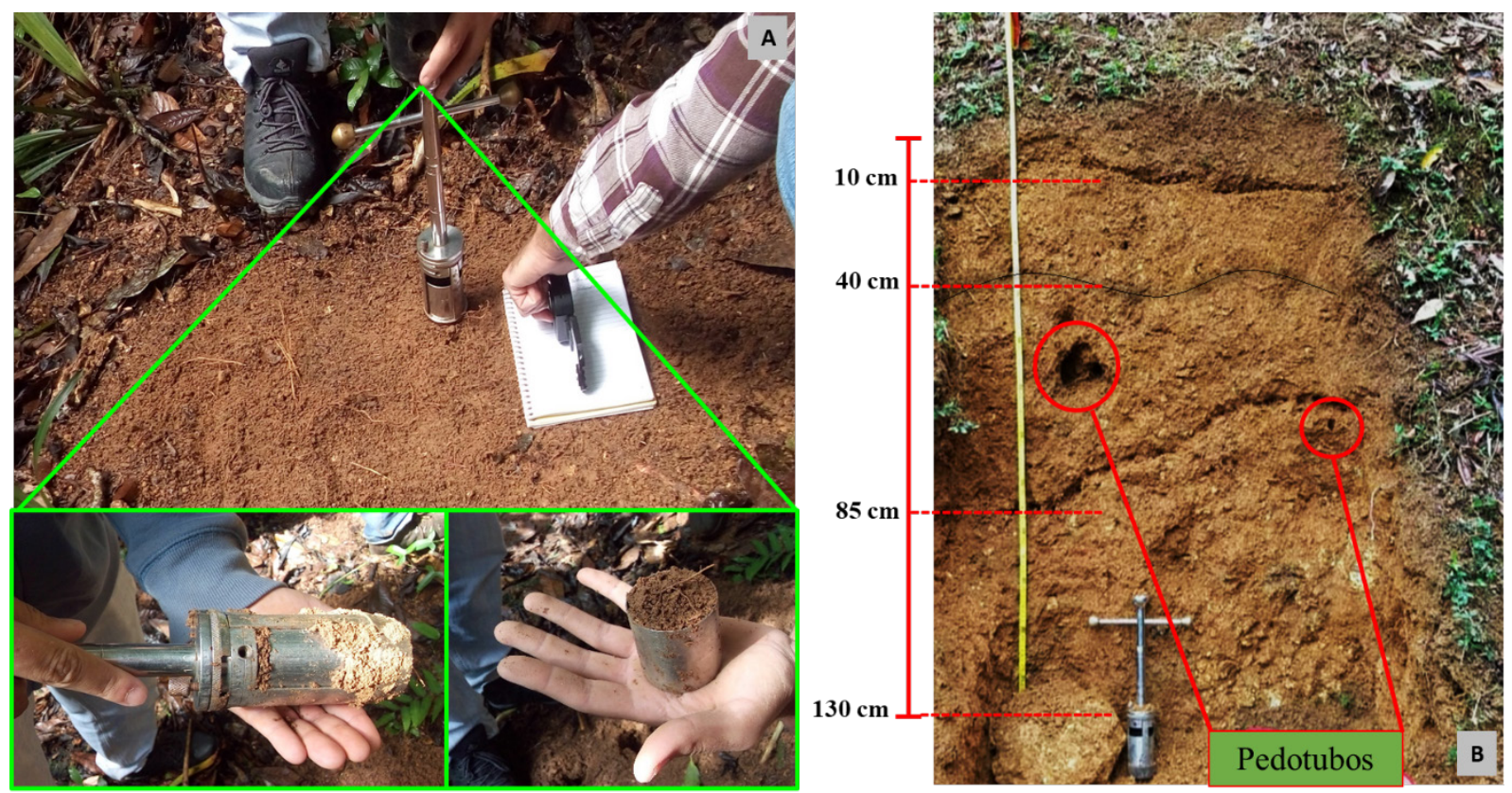

Quadro 1: Descrição dos pontos de coleta de amostras de solo.

\begin{tabular}{|c|c|c|c|}
\hline Pontos de Coleta & $\begin{array}{l}\text { Coordenada } \\
\text { Geográfica }\end{array}$ & Declividade & Características \\
\hline P1 (0-10cm) & $\begin{array}{l}\mathrm{S} 23^{\circ} 28^{\prime} 25.3^{\prime \prime} \\
\text { W0451' } 39.6^{\prime \prime}\end{array}$ & $10^{\circ}$ & $\begin{array}{l}\text { Área de floresta com solo superficial de coloração escura; } \\
\text { presença abundante de serrapilheira. }\end{array}$ \\
\hline P2 (0-10cm) & 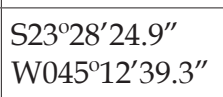 & $13^{\circ}$ & $\begin{array}{l}\text { Área de floresta com solo superficial de coloração escura; } \\
\text { presença abundante de serrapilheira. }\end{array}$ \\
\hline P3 (0-10cm) & 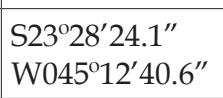 & $9^{\circ}$ & $\begin{array}{l}\text { Área de floresta com solo superficial de coloração escura; } \\
\text { presença abundante de serrapilheira. }\end{array}$ \\
\hline P4 (0-10cm) & $\begin{array}{l}\mathrm{S} 23^{\circ} 28^{\prime} 23.3^{\prime \prime} \\
\mathrm{W} 045^{\circ} 12^{\prime} 39.8^{\prime \prime}\end{array}$ & $20^{\circ}$ & $\begin{array}{l}\text { Área de floresta com solo superficial de coloração escura; } \\
\text { presença abundante de serrapilheira em estágio de } \\
\text { decomposição; solo mais úmido, próximo à cachoeira. }\end{array}$ \\
\hline Perfil & $\begin{array}{l}\mathrm{S} 23^{\circ} 28^{\prime} 25.7^{\prime \prime} \\
\mathrm{W} 045^{\circ} 12^{\prime} 41.1^{\prime \prime}\end{array}$ & $29^{\circ}$ & $\begin{array}{l}\text { Talude de encosta com presença de vegetação superficial; } \\
\text { solo mais escuro superficialmente e mais amarelado com } \\
\text { o aumento da profundidade, presença de pedotubos; } \\
\text { presença de saprolito. }\end{array}$ \\
\hline
\end{tabular}

\section{RESULTADOS E DISCUSSÃO}

\section{Sistema de valoração da geodiversidade de acordo com os serviços ecossistêmicos}

A Avaliação Ecossistêmica do Milênio - Millennium Ecosystem Assessment - foi uma ação coordenada pela Organização das Nações Unidas, entre os anos de 2001 e 2005, visava a definição de parâmetros voltados à gestão sustentável dos ecossistemas. A partir de então, há o reconhecimento da relevância dos serviços ecossistêmicos para a manutenção do bem-estar das sociedades, e com isso, a urgência no que diz respeito à proteção dos ecossistemas (Silva, Mansur \& Nascimento, 2018). 
Por conseguinte, Gray (2013) realizou uma atualização do sistema de valoração para a geodiversidade, composto por 1 valor (intrínseco), 5 serviços (regulação, suporte, provisão, cultural e conhecimento) e 25 bens e processos. O valor intrínseco é conhecido por valor de existência, pois um elemento da geodiversidade possui valor apenas por existir.

O serviço de regulação da geodiversidade está relacionado aos processos responsáveis pelo controle natural das condições ambientais, como os processos atmosféricos, o ciclo hidrológico, o ciclo do carbono e o controle da erosão, os quais proporcionam diversos benefícios para o ser humano, com impactos diretos e indiretos.

O serviço de suporte está relacionado à disponibilidade de recursos da geodiversidade voltados para o desenvolvimento de atividades humanas, estando dependente dos solos, por exemplo, à medida que este elemento se configura em uma parte vital dos sistemas ambientais terrestres, sendo responsável pelo crescimento de plantas, armazenamento de água, habitat, entre outras funções.

O serviço de provisão da geodiversidade está vinculado à disponibilidade de bens materiais que são valorizados pelas sociedades, possuindo valor monetário. Como os diferentes materiais geológicos, por exemplo, indispensáveis para a montagem de aparelhos celulares, como cobre, vidro, alumínio, ferro, silício, níquel, estanho, lítio, cobalto e grafite.

O serviço cultural da geodiversidade diz respeito à relação da sociedade com determinado aspecto abiótico, em virtude do seu significado social ou comunitário. Em diversas áreas, elementos naturais adquirem valor cultural, tendo em vista sua associação às lendas e mitos, justificando, assim, sua geoconservação.

O serviço de conhecimento possui relação com o desenvolvimento das geociências, onde os valores científicos e educacionais da vertente abiótica da natureza são explorados, visando sua proteção e conservação. A exposição de rochas, perfis de solo, fósseis, pode ser utilizada para a educação, contribuindo para disseminação e aprofundamento do conhecimento sobre os processos de origem e evolução da Terra.

\section{SOLOS E VALORES DA GEODIVERSIDADE}

Como ressalta Gray (2013), os solos apresentam valor intrínseco relacionado à sua existência como elemento abiótico que compõe a geodiversidade. Contudo, desempenham também variados serviços ecossistêmicos indispensáveis tanto para a realização das atividades humanas, quanto para o funcionamento equilibrado dos sistemas ambientais.

No que diz respeito ao serviço de regulação da geodiversidade, os solos estão intrinsecamente relacionados a diversos processos que atuam no controle natural das condições ambientais. No ciclo global do carbono, a liberação na forma de CO2 do solo para a atmosfera é considerada um dos fluxos de mais importância na regulação do balanço do carbono atmosférico. O estoque de carbono encontrado nos solos é proveniente de intricados processos e a matéria orgânica do solo (MOS) é responsável por conter a maior quantidade de carbono estocada (Aduan, Vilela \& Klink, 2003; Vezzani \& Mielniczuk, 
2011). Em estudo de 1998, sobre ecossistemas de savana, Scurlock e Hall (1998) estimam que $80 \%$ do carbono total fica armazenado nos solos.

Os solos, assim, desempenham serviço importante de regulação do carbono, estocando e liberando este elemento para a atmosfera, sendo esse um processo indispensável para a manutenção do equilíbrio ambiental e, consequentemente, para as atividades humanas. A qualidade da água também possui relação direta com os solos, juntamente com o substrato rochoso, à medida que ocorre um processo natural de filtragem por meio da infiltração da água no solo e armazenamento subsuperficial. Todavia, o tipo de uso e o manejo dos solos são fatores determinantes no tocante à qualidade da água, o que pode levar ao seu comprometimento pelo uso e manejo inadequados dos solos (Guerra, 2009; Bertoni \& Lombardi Neto, 2010).

Segundo Reichardt (1987), infiltração corresponde ao mecanismo de entrada da água no solo por meio de sua superfície, onde o movimento da água se dá no sentido vertical, de cima para baixo, atingindo as camadas mais profundas do solo. Coelho Netto (2009) atesta que os solos possuem a capacidade de definir a quantidade de água que infiltra ou que excede, escoando na superfície do terreno, de acordo com determinadas características, como a classe textural e a estabilidade de agregados. O trânsito da água na superfície é mais rápido em comparação com o seu trajeto em camadas mais profundas, tornando-se, então, mais lento com o aumento da profundidade. Assim, os solos determinam o volume do escoamento da chuva, como também a sua distribuição temporal e as descargas máximas em superfície e subsuperfície.

Em relação ao serviço de suporte, Vezzani e Mielniczuk (2011) salientam que o solo possui a capacidade de sustentar a produtividade de plantas e animais, manter a qualidade do ar e da água e promover a saúde do ser humano, quando mantida sua qualidade para o seu funcionamento adequado. Christopherson (2012, p. 573) salienta que o solo "é um material dinâmico e natural composto de finas partículas, na qual a vegetação cresce, e que contém fragmentos minerais e material orgânico", e que, entendido como sistema, sustenta toda a vida humana, animal e vegetal na superfície terrestre, sendo fonte importante de informações científicas, como dados sobre a última idade glacial e períodos quentes intervalados, assim como diversos processos físicos. Reichardt (1988) lembra que os solos são meio para a produção de alimentos e fibras, possuem papel relevante para a conservação dos ecossistemas e dos aquíferos, possibilitam a construção de estradas, edifícios e cidades, permitem a compreensão de processos que acontecem durante sua formação, que podem ser utilizados para o entendimento do passado do planeta.

No que diz respeito ao serviço ecossistêmico de provisão, os solos desempenham papel fundamental para a produção de alimentos, sendo o alicerce para o desenvolvimento da agricultura. Possui também importância direta na disponibilização de água para o lençol freático, garantindo o abastecimento de aquíferos. A oferta de água está intrinsecamente relacionada à hidrologia dos solos, responsável pela manutenção da vida vegetal, descargas de base dos mananciais de superfície e regulação dos fluxos de runoff (Oliveira, Ottoni, Ottoni Filho, Macedo \& Rotunno Filho, 2004). Determinadas características dos solos influenciam as taxas de infiltração da água, como a granulometria, estrutura da 
matriz porosa, teor de matéria orgânica, densidade do solo e mineralogia, ou seja, as propriedades morfológicas, físicas e químicas do solo possuem influência direta na maior ou menor oferta de água (Coelho Netto, 2009).

O serviço cultural relacionado aos solos tem ganhado visibilidade por meio do desenvolvimento de estudos etnopedológicos. A abordagem etnopedológica possui como objetivo compreender as relações que determinados grupos sociais estabelecem com os solos, suas percepções deste elemento, classificações, avaliações e usos, que são distintos dos saberes pedológicos formais em ciência do solo. Trata-se de uma área da ciência pedológica de grande relevância, onde há a possibilidade de aliar os saberes populares com o científico, contribuindo para ampliar a gama de conhecimento sobre solos (Posey, 1983; Tabor, 1990; Ortiz-Solorio \& Gutierrez-Castorena, 2001; Matos, Ker, Cardoso, Lani \& Schaefer, 2014).

Diferentes grupos sociais, como as populações camponesas e indígenas, estabeleceram distintas relações com o solo, de acordo com suas visões de mundo. Tais grupos possuem conhecimentos pedológicos locais que são transmitidos de geração em geração, onde o solo é considerado parte indissociável do cotidiano de suas vidas, responsável pela provisão de alimentos, pintura corporal, artesanato, ou seja, os solos possuem importância para esses grupos sociais tanto para fins agrícolas quanto para fins não-agrícolas (Alves, 2005).

No Brasil, diversos estudos têm contribuído para resgatar a memória cultural dos povos, abordando suas relações com os solos. Vale Jr, Schaeffer e Costa (2007), por exemplo, buscaram caracterizar o saber etnopedológico de agricultores da Terra Indígena Malacacheta, no estado de Roraima, identificando as propriedades e características dos solos utilizados por eles e sua vocação para uso agrícola, comparando com o saber científico. Matos, Ker, Cardoso, Lani e Schaefer (2014), por meio de uma estratificação dos ambientes do território quilombola de Brejo dos Crioulos, no estado de Minas Gerais, buscaram identificar, resgatar e valorizar os saberes tradicionais sobre o solo, compreendendo a lógica dos sistemas produtivos desenvolvidos pelos quilombolas.

Do ponto de vista do uso do solo voltado para fins não-agrícolas, estão o artesanato, com a produção de cerâmica realizada por diversos povos; construção de moradias, como as casas de pau-a-pique, também conhecidas como "casas de barro", construídas com a utilização de argila, madeira e palha por diversas comunidades brasileiras; pintura corporal para rituais; geofagia; entre outros (Costa, 1993; Alves, 2005; Silva \& Nascimento, 2019).

Em relação ao serviço de conhecimento, os solos são meio de geração de conhecimento científico, o emprego da sedimentologia e datações absolutas proporcionam avanços importantes para a ciência. Estudos baseados nas análises sedimentológicas e mineralógicas das frações grossas que formam os solos podem apontar para a presença de componentes residuais passados, que não foram perdidos pela ação do intemperismo (Espindola, 2010).

Guerra (2018, p. 112) salienta que "em projetos de geoturismo, os solos podem ser utilizados como instrumento pedagógico, por meio da chamada geoeducação, não só nas universidades, mas também em escolas de ensinos fundamental e médio". Muggler, Pinto Sobrinho e Machado (2006) ressaltam que a conservação dos solos pode ser fomentada por meio da Educação Ambiental, seja integrada nas escolas ou nas comunidades locais, 
através de diferentes atividades, como forma de divulgar conhecimento, transformar atitudes e sensibilizar as pessoas quanto à necessidade de proteção e conservação dos solos, e como isso, auxiliar na mitigação dos riscos socioambientais.

Os solos, portanto, desempenham serviços importantes, pois correspondem aos alicerces da vida em ecossistemas terrestres, dando subsídios tanto para diversas atividades humanas, quanto para a conservação dos ecossistemas. Contudo, torna-se importante compreender o solo por meio de uma visão holística sistêmica, visto ocorrerem interações e fluxos de matéria e energia com seu entorno condicionante. As trocas de energia e matéria são constantes, tanto recebendo, como perdendo. Ao interpretar o solo de uma forma complexa, pode-se contribuir para o entendimento de suas relações com os sistemas componentes, bem como com o ecossistema em que ele pertence, o que pode contribuir para a sua conservação (Vezzani \& Mielniczuk, 2011; Christopherson, 2012; Ibáñez \& Bockheim, 2013; Turetta, Castro \& Polidoro, 2017).

\section{OS VALORES DO SOLO NO SÍTIO PROMATA, DE ACORDO COM OS SERVIÇOS ECOSSISTÊMICOS}

Wang et al. (2019) destacam que os solos são fundamentais para sustentar os serviços ecossistêmicos, e para tal, a qualidade do solo, que pode ser avaliada a partir de suas propriedades físicas e químicas, deve ser preservada, tendo em vista que os solos podem ter limitação natural em exercer suas funções, ou serem perturbados pela ação antrópica, comprometendo a manutenção dos serviços ecossistêmicos a que eles estão intrinsecamente relacionados.

Por conseguinte, o serviço de regulação desempenhado pelos solos corresponde a um serviço ecossistêmico abrangente, à medida que está relacionado, por exemplo, ao acontecimento de processos terrestres, como no ciclo do carbono, por meio da formação e transformação da matéria orgânica, propiciando benefícios que garantem o bem-estar do homem (Andrade \& Romeiro, 2009).

Coletas de amostras de solos volumétricas na área de estudo, podem contribuir para atestar a qualidade do solo e, consequentemente, sua importância na regulação de processos terrestres. Constatou-se que os solos da área possuem características físico-químicas que podem permitir que o solo funcione adequadamente e que, possivelmente, sustente a produtividade de plantas, regule a qualidade do ar e água (Vezzani \& Mielniczuk, 2011). Visto que a densidade aparente variou entre $0,6 \mathrm{~g} / \mathrm{cm}^{3} \mathrm{e} 0,7 \mathrm{~g} / \mathrm{cm}^{3}$, enquanto a porosidade total obteve valores acima de 70\%, nas amostras coletadas de 0-10 cm de profundidade, refletindo a boa estrutura do solo, pois como ressaltam Brady e Weil (2013) o solo entendido como "ideal" deve apresentar porosidade total cima de 50\% (Tab. 1).

Comportamento semelhante pode ser observado no perfil, com valores baixos de densidade do solo e altos de porosidade total, uma vez que são propriedades inversamente proporcionais. Em perfil, pode-se perceber a tendência relatada por determinados autores como Kiehl (1979), Vezzani e Mielniczuk (2011), Brady e Weil (2013) em que a densidade 
aumenta de acordo com a profundidade do solo. Tal comportamento está relacionado à redução natural dos teores de matéria orgânica em profundidade e, consequentemente, da agregação, bem como do peso exercido pelas camadas superiores do solo.

Contudo, mesmo em perfil, a densidade do solo aumenta muito pouco com a profundidade, tendo em vista a boa estrutura do solo, com atuação da matéria orgânica, pois esta é considerada um importante constituinte do solo, que permite maior agregação e coesão entre as partículas, tornando o solo mais poroso e menos denso (Brady \& Weil, 2013). Nesse sentido, o solo analisado parece apresentar boa estrutura, sem compactação superficial e subsuperficial, o que tende a permitir o desenvolvimento de rede porosa adequada ao processo de infiltração e percolação da água no solo, auxiliando para o seu equilíbrio.

Tabela 1: Propriedades físicas e químicas das amostras analisadas.

\begin{tabular}{|c|c|c|c|c|c|c|c|c|c|}
\hline & \multirow{3}{*}{ ANÁLISES } & \multicolumn{8}{|c|}{ AMOSTRAS } \\
\hline & & \multicolumn{4}{|c|}{ PONTOS } & \multicolumn{4}{|c|}{ PERFIL } \\
\hline & & $\begin{array}{l}\text { P1(0- } \\
10 \mathrm{~cm})\end{array}$ & $\begin{array}{l}\text { P2(0- } \\
10 \mathrm{~cm})\end{array}$ & $\begin{array}{r}\mathrm{P3}(0- \\
10 \mathrm{~cm})\end{array}$ & $\begin{array}{l}\text { P4(0- } \\
10 \mathrm{~cm})\end{array}$ & $\begin{array}{l}\mathrm{H1}(0- \\
10 \mathrm{~cm})\end{array}$ & $\begin{array}{l}\mathrm{H} 2(10- \\
40 \mathrm{~cm})\end{array}$ & $\begin{array}{c}\mathrm{H} 3(40- \\
85 \mathrm{~cm})\end{array}$ & $\begin{array}{l}\mathrm{H} 4(85- \\
130 \mathrm{~cm})\end{array}$ \\
\hline \multirow{4}{*}{ 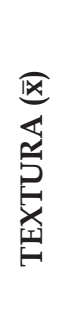 } & AREIA (\%) & 65,53 & 60,7 & 50,95 & 83,11 & 43,35 & 40,86 & 44,95 & 51,51 \\
\hline & SILTE (\%) & 26,12 & 29,94 & 35,92 & 13,89 & 28,91 & 27,93 & 20,47 & 21,05 \\
\hline & ARGILA (\%) & 8,35 & 9,36 & 13,13 & 3 & 27,74 & 31,21 & 34,58 & 27,44 \\
\hline & $\begin{array}{c}\text { CLASSIFICAÇÃO } \\
\text { TEXTURAL }\end{array}$ & $\begin{array}{l}\text { Franco } \\
\text { arenoso }\end{array}$ & $\begin{array}{l}\text { Franco } \\
\text { arenoso }\end{array}$ & Franco & $\begin{array}{l}\text { Areia } \\
\text { franca }\end{array}$ & $\begin{array}{l}\text { Franco } \\
\text { argiloso }\end{array}$ & $\begin{array}{l}\text { Franco } \\
\text { argiloso }\end{array}$ & $\begin{array}{l}\text { Franco } \\
\text { argiloso }\end{array}$ & $\begin{array}{c}\text { Franco } \\
\text { areno- } \\
\text { argiloso }\end{array}$ \\
\hline \multicolumn{2}{|c|}{$\begin{array}{l}\text { DENSIDADE do SOLO } \\
\left(\mathrm{g} / \mathrm{cm}^{3}\right)(\overline{\mathbf{x}})\end{array}$} & 0,7 & 0,6 & 0,7 & 0,6 & 0,6 & 0,7 & 0,7 & 0,7 \\
\hline \multicolumn{2}{|c|}{$\begin{array}{l}\text { POROSIDADE TOTAL } \\
(\%)(\overline{\mathbf{x}})\end{array}$} & 72,2 & 73,6 & 72,2 & 74,7 & 76,4 & 71,2 & 68,5 & 70,3 \\
\hline \multicolumn{2}{|c|}{$\begin{array}{l}\text { MATÉRIA ORGÂNICA } \\
(\%)(\overline{\mathbf{x}}) \\
\end{array}$} & 8,3 & 8,7 & 7,8 & 16,7 & 6 & 4,6 & 3,9 & 3 \\
\hline \multicolumn{2}{|c|}{$\mathrm{pH}(\overline{\mathbf{x}})$} & 4,3 & 4,1 & 4,1 & 4,2 & 4,1 & 4,1 & 4,2 & 4,4 \\
\hline \multirow{3}{*}{$\begin{array}{l}\text { EA } \\
(\overline{\mathbf{x}})\end{array}$} & DMP (mm) & 2,83 & 2,75 & 2,86 & 2,94 & 2,78 & 2,17 & 2,04 & 1,65 \\
\hline & DMG (mm) & 2,66 & 2,48 & 2,69 & 2,89 & 2,41 & 1,69 & 1,56 & 1,07 \\
\hline & IEA (\%) & 97,95 & 96,23 & 97,48 & 99,31 & 94,83 & 89,14 & 88,37 & 74,81 \\
\hline
\end{tabular}

No que diz respeito à análise granulométrica, as amostras coletadas demonstram porcentagens mais elevadas da fração areia, onde a classificação textural variou entre franco arenoso, franco argiloso e areia franca. Já em perfil a distribuição das frações foi mais homogênea, com classificação textural variando entre franco argiloso e franco areno-argiloso. Embora a fração areia tenda a ser menos suscetível ao arraste, de acordo com o seu tamanho de grão, ela não possui as propriedades da fração argila que promovem a agregação das partículas do solo, por sua maior força de coesão. Por isso, as partículas soltas podem ficar mais suscetíveis ao arraste, quando o solo se encontrar desprotegido 
contra a ação erosiva das chuvas, sendo importante a manutenção da cobertura vegetal (Morgan, 2005; Guerra, 2009).

A estabilidade de agregados corresponde a uma propriedade física dos solos muito importante para sua conservação, que quando mantida, fornece proteção à matéria orgânica e resistência à erosão, contribuindo para o equilíbrio e qualidade dos solos. Logo, os solos analisados se apresentaram estáveis em água, com elevados índices de Estabilidade de Agregados (IEA na Tab. 1), o qual representa a agregação total do solo e quanto mais próximo de 100\%, maior será a estabilidade (Silva \& Mielniczuk, 1997; Soares, Maddock, Campos, Madari, Machado \& Santelli, 2018). Este comportamento proporciona resistência aos processos erosivos, pois como ressaltam Guerra e Cunha (1996, p. 359) “a alta estabilidade dos agregados permite maior infiltração, pelo elevado índice de porosidade, diminuindo o escoamento superficial, possibilitando maior resistência do solo ao impacto das gotas de chuva".

Nota-se que em perfil, o índice IEA decresce com o aumento da profundidade. Tal comportamento tende a estar relacionado à diminuição natural da matéria orgânica em profundidade, responsável por conferir maior agregação ao solo, devido sua ação cimentante (Terassi, Silveira \& Bonifácio, 2014). Porém, mesmo em profundidade, o Índice de Estabilidade de Agregados se manteve elevado, caracterizando a boa resistência ao rápido umedecimento do solo.

Comportamento semelhante pode ser observado em relação ao DMP e DMG, os quais apresentaram mais agregados menores do que $2 \mathrm{~mm}$ em perfil, com o aumento da profundidade. Lima, Pauletto, Gomes e Silva (2003), Terassi, Silveira e Bonifácio (2014) e Souza, Melo, Chaves, Prado, Brito Filho e Santos (2019) também verificaram redução do DMP em profundidade, relacionando este fato às reduções nos teores de matéria orgânica. A mesma situação pôde ser observada por Suzuki, Lima, Reinert, Reichert e Pillon (2014), ao realizarem estudo de impacto sobre Argissolo Vermelho submetido a diferentes usos.

Logo, a vegetação exerce papel importante, onde a matéria orgânica funciona como elemento preponderante para a formação de agregados e, consequentemente, para a boa estrutura dos solos e resistência em relação aos processos erosivos. Pois como ressaltam Castro Filho, Muzilli e Podanoschi (1998) e Soares et al. (2018), a presença de agregados grandes tende a conferir ao solo resistência à erosão, uma vez que os espaços porosos entre os agregados são maiores, aumentando a infiltração da água da chuva e, portanto, diminuindo a atuação do escoamento superficial.

Segundo Morgan (2005), os teores de matéria orgânica abaixo de 3,5\% aumentam a suscetibilidade dos solos aos processos erosivos. Assim, os valores de matéria orgânica encontrados, acima de 3,5\%, podem auxiliar contra a erosão, ajudando na agregação das partículas do solo e na infiltração da água. Somente o ponto H4 do perfil obteve média inferior, o que pode estar ligado a diminuição natural da matéria orgânica de acordo com o aumento da profundidade.

Assim, levando em consideração que teores de matéria orgânica abaixo de 3,5\% aumentam a suscetibilidade dos solos aos processos erosivos, assim como destaca Morgan (2005), os valores de matéria orgânica encontrados, acima de 3,5\%, (exceto o ponto H4 do 
perfil, tendo em vista a diminuição natural da matéria orgânica de acordo com o aumento da profundidade) auxiliam contra a erosão, ajudando na agregação das partículas do solo e na infiltração da água.

Os valores mais elevados nas coletas de $0-10 \mathrm{~cm}$, quando comparados aos valores em perfil, são justificáveis em decorrência da menor profundidade de coleta. Pois como chamam a atenção Zinn, Lal e Resck (2011), a variação na quantidade de matéria orgânica do solo é dependente de uma série de fatores, como os resíduos acumulados na superfície, clima, textura e profundidade do solo. $\mathrm{O}$ ponto $\mathrm{P} 4$ corresponde àquele mais próximo à cachoeira, com bastante acúmulo de serrapilheira em estágio de decomposição, de acordo com a umidade mais expressiva em comparação aos demais pontos de coleta.

A manutenção da cobertura vegetal é imprescindível para proporcionar aos solos teores de matéria orgânica adequados. Para Vezzani e Mielniczuk (2011), os vegetais são os principais responsáveis pela adição ao solo de compostos orgânicos, que, posteriormente, contribuirão para a agregação das partículas do solo. Porém, a matéria orgânica é passível de ser perdida rapidamente, visto que é altamente sensível às alterações de uso e manejo.

A análise do $\mathrm{pH}$, por sua vez, apresentou resultados semelhantes nas amostras investigadas, resultados que demonstram a existência de solos ácidos, variando entre 4,1 e 4,4. Rossi (1999), Rodrigues (2016) e Jorge (2017) ressaltam que o $\mathrm{pH}$ dos solos nessa região dificilmente ultrapassa o valor de 5,0, tendo em vista os elevados teores de carbono orgânico, que aumentam os valores de alumínio trocável. Os altos índices pluviométricos, por sua vez, atuam na lixiviação das bases (Ca e $\mathrm{Mg}$, por exemplo) presentes no solo, deixando íons $\mathrm{H}+$ em seu lugar.

Nesta perspectiva, as propriedades físico-químicas dos solos podem ser consideradas um indicador de sua qualidade, ou seja, a capacidade do solo de funcionar adequadamente e regular os serviços ecossistêmicos. Vezzani e Mielniczuk (2011, p. 82) destacam que

A qualidade do solo está associada ao nível de complexidade alto, onde as propriedades emergentes capacitam o sistema solo exercer suas funções na natureza. Para o sistema funcionar e atingir estados de ordem em nível de complexidade alto, é necessário ter fluxo de magnitude alta e velocidade baixa para que a grande quantidade de energia e matéria adicionada no sistema conduza-o à auto-organização em estruturas complexas e que estas persistam por maior tempo possível.

Portanto, constatou-se que os solos analisados possuem características físico-químicas que garantem sua qualidade, sendo assim, os solos podem atuar na regulação de importantes serviços para o bem-estar do ser humano, por isso a importância de sua conservação, que pode ser assegurada por meio de atividades que demonstrem seu valor.

É necessário atentar para localidades que se situam nas proximidades do Sítio PROMATA, que abrigam a extração mineral para a construção civil. Apesar de acontecer, na maioria das vezes, de forma clandestina, a extração mineral também pode ser considerada um serviço ecossistêmico de provisão relacionado aos solos, de acordo com seu valor monetário para o homem (Fig. 6). 
Figura 6: Explotação mineral de saprolito em Ubatuba, SP.

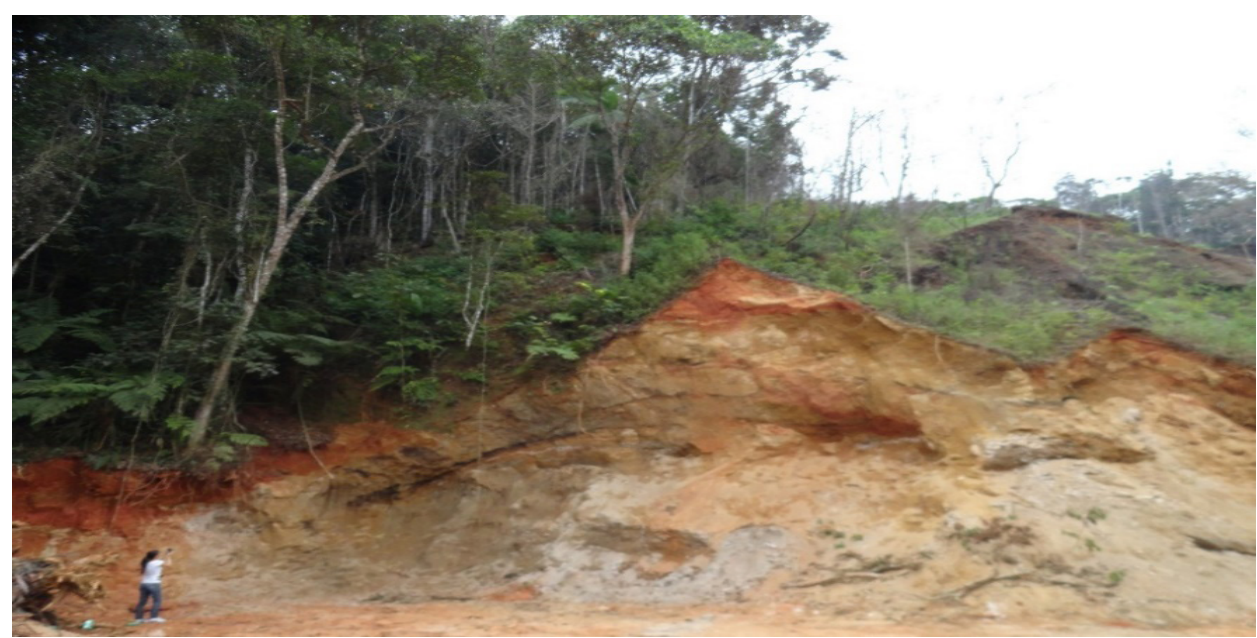

Foto: L. Pereira, 2014.

O saprolito é amplamente extraído em Ubatuba e corresponde a um material incoerente que ainda preserva as características do tecido primário rochoso, mas com algum sinal de intemperismo químico (McQueen \& Scott, 2009). Para o IBGE (2004, p. 275) saprolito é um "material proveniente da decomposição química incompleta de rochas feldspáticas leucocráticas (granitos e gnaisses), conservando vestígios da estrutura/textura original"

A explotação mineral acontece com alta regularidade, onde o saprolito é usado nas misturas de cimento e areia na construção civil (Rodrigues, Pereira, Jorge \& Guerra, 2018). Quando realizado de forma correta, minimizando possíveis impactos ambientais, por meio da correta finalização da lavra, com a recuperação da cobertura vegetal, a explotação mineral pode significar a produção de bens materiais para o ser humano.

O solo também é utilizado como importante recurso para o desenvolvimento de atividades humanas, como a agricultura e moradia, caracterizando o serviço ecossistêmico de suporte (Fig. 7).

Figura 7: Resquícios da plantação de bananas na área de estudo (A); Estrutura de uma casa de pau-a-pique no Sítio PROMATA (B).

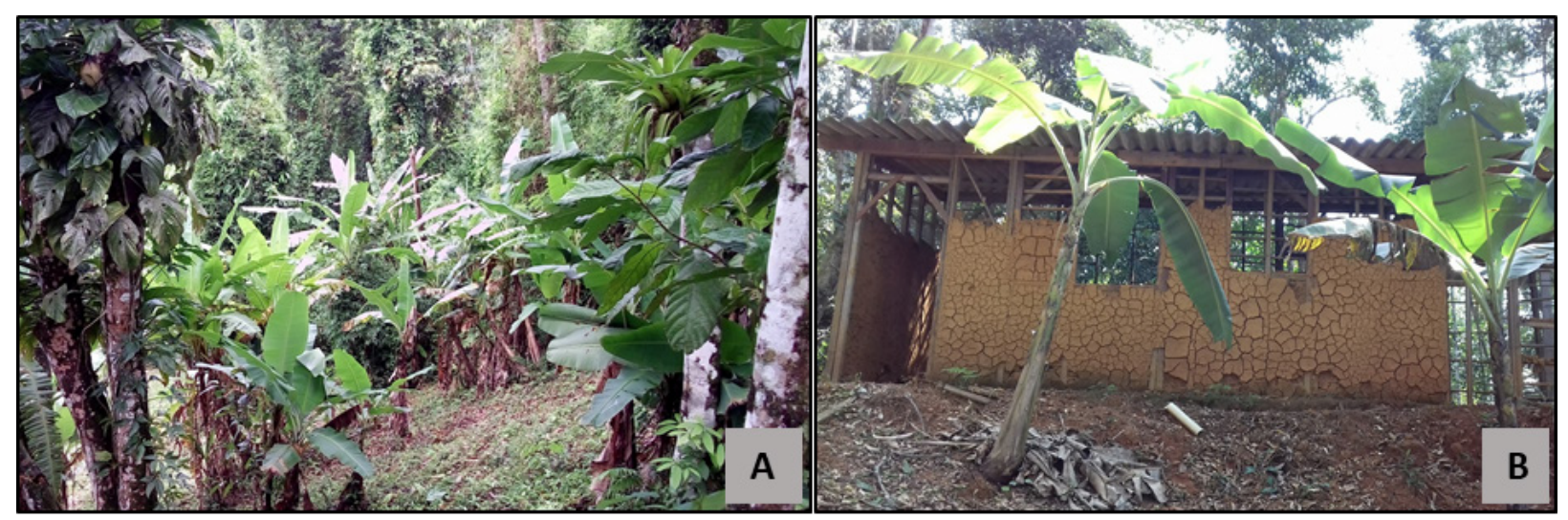

Fotos: A.M. Rodrigues, 2018. 
A agricultura, hoje não mais praticada e nem permitida na área, foi impulsionada por iniciativas governamentais, destacando-se a plantação de bananas. A cultura da bananeira não se restringiu somente à bacia do rio Escuro, mas esteve presente ao longo do planalto e do litoral dos demais municípios que compõem o litoral Norte do Estado de São Paulo, principalmente entre as décadas de 1960/70, caracterizando-se como a atividade agrícola mais importante nesse período (Coelho \& Audi, 1966).

A expansão da cultura de bananas foi possível em virtude das condições naturais da área, como clima quente e úmido e solos com propriedades físicas e químicas adequadas. Nesta perspectiva, durante a década de 1960/70, chegaram a ser cultivados 363,0 ha $(227.000$ pés de bananeira) de bananas nos solos das partes baixas do município de Ubatuba, e 42,6 ha (47.000 pés de bananeira) nos solos das partes altas (Coelho \& Audi, 1966).

$\mathrm{Na}$ atualidade, as populações caiçaras de Ubatuba ainda estabelecem uma relação íntima de interação com os solos, praticando agricultura com elevada diversidade de espécies cultivadas, sendo a produção de banana e mandioca as principais, correspondendo à base da atividade agrícola em Unidades de Conservação, além de outras frutas e hortaliças para subsistência e comercialização local (Macêdo, 2014; Jorge, 2017).

Os caiçaras também utilizavam o solo na estrutura de suas casas, as chamadas casas de pau a pique, que são exemplares de sua cultura e da íntima interação que as populações tradicionais estabeleciam com o meio natural. As habitações caiçaras eram moldadas com materiais encontrados na natureza, como madeira e solo, basicamente, o qual era utilizado para erguer as paredes.

O serviço cultural, por sua vez, pode ser justificado pelo significado cultural e histórico relacionado aos solos da área, uma vez que as populações tradicionais faziam diferentes usos dos mesmos, desde os Tupinambás, primeiros habitantes, passando pelas populações escravizadas e, por último, o povo miscigenado conhecido como caiçara. Por meio do solo, diferentes utensílios eram fabricados, de acordo com o trabalho artesanal do caiçara. Crenças e mitos também estão alicerçados na relação com os elementos naturais (Maranduba News, 2012; 2016).

Os patrimônios natural e cultural possuem intrínsecas relações, a partir do conhecimento sobre a história e cultura de uma sociedade, onde a interpretação a respeito do meio natural pode ser realizada de forma mais completa, visto que um determinado elemento abiótico pode conter significados variados para cada indivíduo ou grupo social (Alves, 2005; Silva \& Nascimento, 2019). Nesse sentido, as habitações tipicamente caiçaras, de pau a pique, também estão relacionadas ao viés cultural, representando um modo de vida baseado no uso dos recursos naturais, que passaram a constituir a base da identidade de uma comunidade. As formas de uso e apropriação dos solos correspondem a um conhecimento transmitido de geração em geração e caracterizam a riqueza cultural dos caiçaras e sua relação com este elemento abiótico.

O serviço cultural tende a constituir, portanto, um importante serviço ecossistêmico não associado somente com benefícios materiais. Mas implica, sobretudo, no resgate e valorização de modos de vida, em um momento em que a identidade caiçara tende a se diluir com a inserção de novos costumes e valores, principalmente em virtude da perda 
de territórios. Ressalta-se que não é o caso de considerar a cultura caiçara como superior ou inferior a qualquer outra, pelo contrário, busca-se demonstrar e valorizar o multiculturalismo que caracteriza a sociedade e corresponde a uma riqueza imensurável.

A utilização científica e educacional, relacionada ao serviço de conhecimento, é parte importante no processo de conservação dos solos, onde os estudos que versam sobre a dinâmica pedológica da área podem ser transmitidos para a comunidade local, como forma de conscientização e mudanças de atitude na relação com o meio natural. Pesquisas científicas que envolvem os solos já foram realizadas em localidades próximas à bacia hidrográfica do rio Escuro. Mais recentemente, podem ser destacados os estudos realizados por Rodrigues (2016), Pereira, Rodrigues, Jorge, Guerra e Fullen (2016) e Jorge (2017). No Sítio PROMATA, pesquisas em solos estão sendo realizadas com o objetivo de informar a população quanto a importância deste elemento abiótico, visando o fomento da educação, bem como a possível geração de empregos, a partir do uso dos recursos abióticos adequadamente, em uma área com vocação turística (Fig. 8).

Figura 8: Realização de atividades científica e educacional na área de estudo.
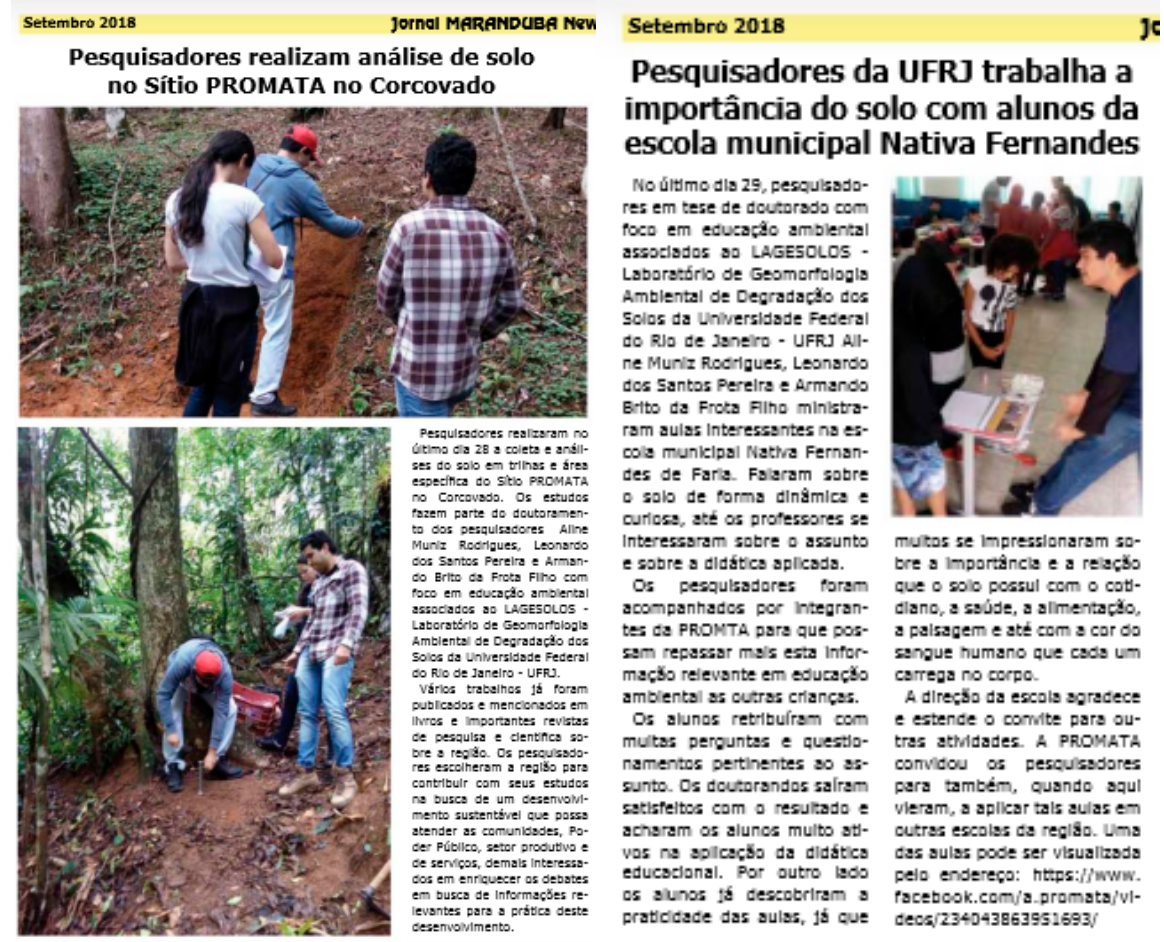

Fonte: Maranduba News (2018).

O serviço de conhecimento é muito importante para as Geociências, pois permite conhecer e interpretar os elementos abióticos, auxiliando, assim, em sua conservação. A divulgação sobre a relevância da geodiversidade para a vida pode contribuir para a formação de cidadãos mais conscientes quanto ao seu papel na proteção dos elementos naturais, como o solo, o qual ainda permanece muito distante da população em geral e, por isso, demanda esforços para torná-lo mais familiar. 
Turetta, Castro e Polidoro (2017, p. 29) finalizam ressaltando que "assim como outros recursos naturais, o solo provê uma série de serviços para, além dos ecossistemas, a sociedade e, ao se valorar esses benefícios, pode-se ter uma dimensão da importância desse "ativo". Contudo, ainda há carência de pesquisas que envolva o solo e a prestação de serviços ecossistêmicos, principalmente nacionais, apesar do crescimento de estudos sobre degradação e educação em solos nos últimos anos.

Assim, os solos possuem variados valores, registram também a história e cultura de um povo, e são importantes para manutenção do equilíbrio ambiental e provisão dos serviços ecossistêmicos. Os povos que habitaram, ou utilizaram o Sítio PROMATA e seu entorno, como passagem, fizeram usos distintos dos solos, onde os mesmos podem ser fontes importantes de informações sobre seu modo de vida e, como parte da geodiversidade. É dotado de uma gama de valores, dentre eles se destacam o cultural, científico e didático (Apêndice 1).

\section{CONSIDERAÇÕES FINAIS}

Conclui-se, portanto, que a realização de estudos que utilizem o sistema de valoração da geodiversidade, baseado em serviços ecossistêmicos, pode auxiliar na divulgação da vertente abiótica da natureza, e, por sua vez, contribuir para a valorização e conservação dos elementos abióticos, como os solos, um elemento dotado de valor, que desempenha importantes serviços ecossistêmicos, indispensáveis para garantir a qualidade de vida das sociedades. A falta de conhecimento sobre a prestação de serviços ecossistêmicos, e sobre os solos, em geral, pode implicar no agravamento de sua degradação.

Assegurar a boa estrutura dos solos, preservando suas propriedades físicas e químicas, constitui aspecto indispensável para a provisão de serviços ecossistêmicos e equilíbrio ambiental. Logo, a partir da realização de análises físicas e químicas no Sítio PROMATA, constatou-se que os solos se apresentam em bom estado de conservação, o que pode auxiliar na capacidade de exercer suas funções ecossistêmicas e manter o ambiente em equilíbrio. A ênfase no estudo dos solos da área pode contribuir para a melhor proteção ambiental em Unidades de Conservação, a partir da realização de visitas guiadas, com profissionais capacitados, com alunos de escolas municipais, por exemplo. Ampliando assim as ações de educação ambiental preconizadas em áreas protegidas, primordiais para alcançar a geoconservação.

Nesta perspectiva, a valoração dos solos, baseada nos serviços ecossistêmicos, confirmou que todos os serviços são possíveis de serem desempenhados pelo solo, e que este elemento possui elevado valor dentro do quadro da geodiversidade, onde seu estudo e divulgação compreendem importantes instrumentos voltados para a geoconservação. Salienta-se a importância do serviço cultural dos solos, alicerçado em sua utilização científica e educacional, o que tende a contribuir para seu uso e manejo adequados. 


\section{AGRADECIMENTOS}

À Coordenação de Aperfeiçoamento de Pessoal de Nível Superior - CAPES - pela concessão das bolsas de pós-graduação aos autores 1 e 2, e à Fundação de Amparo à Pesquisa do Estado do Rio de Janeiro - FAPERJ pelo suporte ao autor 3. Ao Sr. Manoel Cabral e Ezequiel dos Santos, pelo apoio logístico nos trabalhos de campo.

\section{REFERÊNCIAS}

Aduan, R.E., Vilela, M.F., \& Klink, C.A. (2003). Ciclagem de carbono em ecossistemas terrestres - o caso do Cerrado brasileiro. Planaltina: Embrapa Cerrados (Documentos). Retirado de https://ainfo.cnptia.embrapa. br/digital/bitstream/item/40543/1/Ciclagem-de-Carbono-em-Ecossistemas-Terrestres-O-Caso-doCerrado-Brasileiro-.pdf.

Alves, Â.G.C. (2005). Conhecimento local e uso do solo: uma abordagem etnopedológica. Interciência, 30(9):524-528.

Andrade, D.C., \& Romeiro, A.R. (2009). Capital natural, serviços ecossistêmicos e sistema econômico: rumo a uma "Economia dos Ecossistemas". Campinas: IE/UNICAMP. (Texto para Discussão, 159).

Arruda, K.E.C., Garcia, M.G.M., \& Del Lama, E.A. (2017). Inventário Geológico do Patrimônio Construído no Litoral Norte do Estado de São Paulo, Brasil. Boletim Paranaense de Geociências, 73:15-33. DOI: http:// dx.doi.org/10.5380/geo.v73i1.50120.

Bertoni, J., \& Lombardi Neto, F. (2010). Conservação do solo. 7a.ed. São Paulo: Ícone.

Botelho, R.G.M., Pelech, A.S., \& Souza, R.A. (2018). Retrato e valor(iz)ação da geodiversidade brasileira. Seminário de Metodologia. Rio de Janeiro: IBGE. Retirado de https://eventos.ibge.gov.br/downloads/ smi2018/resumos/apresentacoesorais/OR4\%20-\%20Rosangela\%20Botelho.pdf.

Brady, N.C., \& Weil, R.R. (2013). Elementos da natureza e propriedades dos solos. 3a. ed. Porto Alegre: Bookman. Brilha, J. (2016). Inventory and quantitative assessment of Geosites and Geodiversity sites: a review. Geoheritage, 8(2):119-134. https://doi.org/10.1007/s12371-014-0139-3

Castro Filho, C., Muzilli, O., \& Podanoschi, A. L. (1998). Estabilidade dos agregados e sua relação com o teor de carbono orgânico num Latossolo Roxo Distrófico, em função de sistemas de plantio, rotações de culturas e métodos de preparo das amostras. Revista Brasileira de Ciência do Solo, 22:527-538. https://doi. org/10.1590/S0100-06831998000300019.

Christopherson, R.W. (2012). Geossistemas: uma introdução à Geografia Física. 7a. ed. Porto Alegre: Bookman. Coelho Netto, A.L. (2009). Hidrologia de encostas na interface com a Geomorfologia. In A.J.T. Guerra, \& S.B. Cunha (Org.). Geomorfologia: uma atualização de bases e conceitos. (9a. ed., pp. 93-148). Rio de Janeiro: Bertrand Brasil.

Coelho, A.G.S., \& Audi, R. (1966). Aspectos da Bananicultura no Litoral Norte Paulista Estudados através de Fotografias Aéreas. Boletim Científico do Instituto Agronômico do Estado de São Paulo, 25(8):87-94.

Comitê de Bacias Hidrográficas do Litoral Norte (2017). Relatório II do Plano de Bacias Hidrográficas do Litoral Norte de São Paulo UGRHI 03 2016-2019. São José dos Campos. Retirado de http://www.sigrh.sp.gov.br/ public/uploads/documents/ /CBH-LN/13694/relatorio-2-ugrhi3.pdf

Conway, J. (2010). A soil trail? A case study from Anglesey, Wales, UK. Geoheritage, 2(1):15-24.

Costa, C.Z. (1993). O desenho cultural da arquitetura Guarani. Pós, (4):113-130. http:/ / dx.doi.org/10.11606/ issn.2317-2762.v0i4p113-130.

Cruz, O. (1990). Contribuição geomorfológica ao estudo de escarpas da Serra do Mar. Rev. IG, 8-11(1): 9-20. DOI: http://dx.doi.org/10.5935/0100-929X.19900002. 
Empresa Brasileira de Pesquisa Agropecuária (2011). Manual de métodos de análise de solo. 2a. ed. Rio de Janeiro: Centro Nacional de Pesquisa de Solos.

Espindola, C.R. (2010). A pedologia e a evolução das paisagens. Revista do Instituto Geológico, 31(1/2):67-92.

Fierz, M.S.M. (2008). As abordagens sistêmica e do equilíbrio dinâmico na análise da fragilidade ambiental do litoral do estado de São Paulo: contribuição à geomorfologia das planícies costeiras. (Tese de Doutorado em Geografia). Universidade de São Paulo, USP, São Paulo, SP, Brasil.

Fontes, L.E.F., \& Muggler, C.C. (1999). Educação não formal em solos e o meio ambiente: desafios na virada do milênio. Congreso Latino Americano de la Ciencia del Suelo, Pucón, Araucania, Chile, 14. p. 833.

Garcia, M.G.M., Del Lama, E.A., Bourotte, C.L.M., Mazoca, C.E.M., Bacci, D., \& Santos, V.M.N. (2017). Geoheritage inventories as means, not ends: exemple of the coastal region of São Paulo state, Brazil. Patrimonio geológico, gestionando la parte abiótica del patrimônio natural. Cuadernos del Museo Geominero, 21:131-136.

Gobbi, E.S., \& Ladeira, F.S.B. (2011). Proposta para mapeamento de riscos associados a movimento de massa e inundação: o caso de Ubatuba, SP. Geociências, 30(3):445-456.

Gray, M. (2013). Geodiversity: valuing and conserving abiotic nature. 2a ed. Chichester: John Wiley \& Sons.

Guerra, A.J.T. (2009). Processos Erosivos nas Encostas. In Guerra, A.J.T., \& Cunha, S.B. Geomorfologia: uma atualização de bases e conceitos. 9a. ed. Rio de Janeiro: Bertrand Brasil.

Guerra, A.J.T. (2018). O papel dos solos sob a ótica do geoturismo, da geodiversidade e da geoconservação. In A.J.T Guerra, \& M.C.O. Jorge (Org.). Geoturismo, geodiversidade e geoconservação: abordagens geográficas e geológicas. São Paulo: Oficina de Textos.

Guerra, A.J.T., \& Cunha, S.B. (1996). Degradação Ambiental. In A.J.T. Guerra, \& S.B. Cunha. Geomorfologia e meio ambiente. Rio de Janeiro: Bertrand Brasil.

Ibáñez Martí, J.J., \& Bockheim, J. (2013). Pedodiversity. Boca Raton: CRC Press.

Instituto Brasileiro de Geografia e Estatística (2004). Vocabulário básico de recursos naturais e meio ambiente. 2a. ed. Rio de Janeiro.

Instituto Brasileiro de Geografia e Estatística (2015). Manual Técnico de Pedologia. 3a. ed. Rio de Janeiro. Retirado de https:/ / biblioteca.ibge.gov.br/visualizacao/livros/liv95017.pdf

Jorge, M.C.O. (2017). Potencial geoturístico e estratégias de geoconservação em trilhas situadas na região sul do município de Ubatuba. (Tese de Doutorado em Geografia). Universidade Federal do Rio de Janeiro, UFRJ, Rio de Janeiro, RJ, Brasil.

Jorge, M.C.O., Guerra, A.J.T., \& Fullen, M.A. (2016). Geotourism, Geodiversity and Geoconservation in Ubatuba Municipality, São Paulo State, Brazil. Geography Review, 29:23-29.

Karlen, D.L., Mausbach, M.J., Doran, J.W., Cline, R.G., Harris, R.F., \& Schuman, G.E. (1997). Soil quality: a concept, definition and framework for evaluation. Soil Science Society America Journal, 61(1): 4-10. https:// doi.org/10.2136/sssaj1997.03615995006100010001x.

Kiehl, E.J. (1979). Manual de edafologia: relações solo-planta. São Paulo: Ceres.

Lima, C.L.R., Pauletto, E.A., Gomes, A.S., \& Silva, J.B. (2003). Estabilidade de agregados de um Planossolo sob diferentes sistemas de manejo. Revista Brasileira de Ciência do Solo, 27:199-205.

Macêdo, G.S.S.R. (2014). Espécies Hortícolas Alimentares da População Caiçara do Sertão de Ubatumirim, Litoral Norte de São Paulo: Manejo e Paisagem. (Dissertação de Mestrado). Universidade Estadual Paulista, UNESP, Botucatu, SP, Brasil. Retirado de http://hdl.handle.net/11449/110958.

Matos, L.V., Ker, J.C., Cardoso, I.M., Lani, J.L., \& Schaefer, C.E.G.R. (2014). O conhecimento local e a etnopedologia no estudo dos agroecossistemas da Comunidade Quilombola de Brejo dos Crioulos. Sociedade \& Natureza, 26(3):497-510. http:/ / dx.doi.org/10.1590/1982-451320140308

Mazzucato, E. (2017). Estratégias de geoconservação no Parque Estadual da Serra do Mar - núcleos Picinguaba e Caraguatatuba (SP). (Dissertação de Mestrado). Universidade de São Paulo, IGc/USP, São Paulo, SP, 
Brasil. Retirado de https://teses.usp.br/teses/disponiveis/44/44144/tde-25042018-153746/publico/ Dissertacao_ElianaMazzucato.pdf.

McQueen, K.G., \& Scott, K.M. (2009). Rock weathering and structure of the regolith. In K. Scott, \& C.F. Pain (eds.). Regolith Science. Dordrecht: Springer Science.

Ministério do Meio Ambiente. Biomas/Mata Atlântica. Retirado de http://www.mma.gov.br/biomas/ mata-atlântica_emdesenvolvimento.

Mochiutti, N.F., Guimarães, G.B., \& Melo, M.S. (2011). Os valores da geodiversidade da região de Piraí da Serra, Paraná. Geociências, 30(4):651-668.

Morgan, R.P.C. (2005). Soil Erosion and Conservation. London: Blackwell.

Mucivuna, V.C. (2016). Estratégias de geoconservação aplicadas à geodiversidade do município de Bertioga - SP e às fortificações do litoral paulista. (Dissertação de Mestrado). Universidade de São Paulo, IGc/USP, São Paulo, SP, Brasil.

Muggler, C.C., Pinto Sobrinho, F.A., \& Machado, V.A. (2006). Educação em solos: princípios, teoria e métodos. Revista Brasileira de Ciência do Solo, 30:733-740.

Oliveira, M.B., Ottoni, M.V., Ottoni Filho, T.B., Macedo, J.R., \& Rotunno Filho, O.C. (2004). Análise do desempenho de equações de infiltração em solos de uma Bacia Hidrográfica de São José de Ubá, RJ. Simpósio de Recursos Hídricos do Nordeste, São Luís, MA, Brasil, 7. 12 p.

Ortiz-Solorio, C.A., \& Gutierrez-Castorena, M. del C. (2001). La etnoedafologia en Mexico, uma vision retrospective. Rev. Etnobiologia, 1:44-62.

Pedra Rachada - muitos mistérios cercam este lugar secular. (2016, setembro). Maranduba News, 5(64):8. Recuperado de https://issuu.com/maranduba/docs/ jornalmarandubanews64web?viewMode=doublePage.

Pereira, L.S. (2019). Análise hidroerosiva de trilha em encosta: métodos e técnicas de monitoramentos geomorfológicos para a geoconservação. (Tese de Doutorado em Geografia). Universidade Federal do Rio de Janeiro, UFRJ, Rio de Janeiro, RJ, Brasil.

Pereira, L.S., Rodrigues, A.M., Jorge, M.C.O., Guerra, A.J.T., \& Fullen, M.A. (2016) Processos hidro-erosivos em solos degradados em relevo de baixa declividade. Revista Brasileira de Geomorfologia, 17(2):299-316. http://dx.doi.org/10.20502/rbg.v17i2.877.

Pesquisadores da UFRJ trabalham a importância do solo com alunos da escola municipal Nativa Fernandes. (2018, setembro). Maranduba News, 9(112):5. Recuperado de https://jornalmaranduba.com.br/jornalmaranduba-news-112/

Pico do Corcovado: 1.160 metros de aventura e mistério. (2012, janeiro). Maranduba News, 3(33):9. Recuperado de https://issuu.com/maranduba/docs/jornalmarandubanews33web?viewMode=magazine.

Ponçano, W.L., Almeida, F.F.M., Carneiros, C.D.R., Bistrichi, C.A., Pires Neto, A.G., Almeida, M.A., ..., \& Santos, M.C.S.R. (1981). Mapa geomorfológico do Estado de São Paulo. São Paulo: PROMOCET/ IPT. v.1.

Posey, D.A. (1983). Indigenous knowledge and development: an ideological bridge to the future. Ci.. Cult., 35:877-894.

Reichardt, K. (1987). A água em sistemas agrícolas. São Paulo: Manole.

Reichardt, K. (1988). Por que estudar o solo? Congresso Brasileiro de Ciência do Solo, Campinas, São Paulo, Brasil, 21. pp.75-78.

Rodrigues, A.M. (2016). Diagnóstico da Degradação do Solo de Taludes de Corte na Bacia Hidrográfica do Rio Maranduba - Ubatuba/SP. (Dissertação de Mestrado em Geografia). Universidade Federal do Rio de Janeiro, UFRJ, Rio de Janeiro, RJ, Brasil.

Rodrigues, A.M., Pereira, L.S., Jorge, M.C.O., \& Guerra, A.J.T. (2018). Análises físico-químicas de solo de taludes de corte de mineração: o contexto ambiental da bacia hidrográfica do rio Maranduba, Ubatuba/SP. Caminhos de Geografia, 19(67):157-174. https:/ / doi.org/10.14393/Hygeia196711. 
Rossi, M. (1999). Fatores formadores da paisagem litorânea: a bacia do Guaratuba, São Paulo - Brasil. (Tese de Doutorado em Geografia Física). Universidade de São Paulo, USP, São Paulo, SP, Brasil.

Rossi, M. (2017). Mapa pedológico do Estado de São Paulo. rev. e ampl. São Paulo: Instituto Florestal.

Sant'Anna Neto, J.L. (1990). Ritmo climático e a gênese das chuvas na zona costeira paulista. (Dissertação de Mestrado). Universidade de São Paulo, USP, São Paulo, SP, Brasil.

Santos, Á.R. (2004). A grande barreira da Serra do Mar: da trilha dos Tupiniquins à Rodovia dos Imigrantes. São Paulo: O Nome da Rosa.

Santos, P.L.A. (2014). Patrimônio geológico em áreas de proteção ambiental: Ubatuba - SP. (Dissertação em Mestrado). Universidade de São Paulo, IGc/USP, São Paulo, SP, Brasil.

Scurlock, J.M.O, \& Hall, D.O. (1998). The Global Carbon Cycle: A Grassland Perspective. Global Change Biology, 4:229-233.

Silva, I.F., \& Mielniczuk, J. (1997). Avaliação do estado de agregação do solo afetado pelo uso agrícola. Revista Brasileira de Ciência do Solo, 21:313-319.

Silva, M.L.N., \& Nascimento, M.A.L. (2016). Os valores da geodiversidade de acordo com os serviços ecossistêmicos sensu Murray Gray aplicados a estudos in situ na cidade de Natal (RN). Caderno de Geografia, 26(2):338-354. https:// doi.org/10.5752/p.2318-2962.2016v26nesp2p338.

Silva, M.L.N., \& Nascimento, M.A.L. (2019). O sistema de valoração da geodiversidade, com enfoque nos serviços ecossistêmicos sensu Murray Gray. Boletim do Museu Paraense Emílio Goeldi, 14(1):79-90. Retirado de http:/ / editora.museu-goeldi.br/bn/artigos/cnv14n1_2019/sistema(silva).pdf.

Silva, M.L.N., Mansur, K.L., \& Nascimento, M.A.L. (2018). Serviços Ecossistêmicos da Natureza e sua Aplicação nos Estudos da Geodiversidade: uma Revisão. Anuário do Instituto de Geociências, 41(2):699-709. http://dx.doi.org/10.11137/2018_2_699_709.

Soares, R., Maddock, J.E.L., Campos, D.V.B., Madari, B.E., Machado, P.L.O., \&Santelli, R.E. (2018). Avaliação da Estabilidade de Agregados em Marcadores Ambientais Terrestres do Antropoceno Submetidos a Diferentes Períodos de Pousio. Revista Virtual de Química, 10(6):1693-1718. https:/ / doi.org/10.21577/19846835.20180114.

Souza, F.G., Melo, V.F., Chaves, J.S., Prado, R.J., Brito Filho, E.G., \& Santos, E.A.N. (2019). Atributos físicos, mineralogia e compactação do solo em ambientes naturais no extremo norte da Amazônia, Brasil. Revista EDUCAmazônia, 23(2):154-167.

Suzuki, L.E.A.S., Lima, C.L.R., Reinert, D.J., Reichert, J.M. \& Pillon, C.N. (2014). Estrutura e armazenamento de água em um Argissolo sob pastagem cultivada, floresta nativa e povoamento de eucalipto no Rio Grande do Sul. Revista Brasileira de Ciência do Solo, 38:94-106. https:/ / doi.org/10.1590/S0100-06832014000100009.

Tabor, J. (1990). Ethnopedology: using indigenous knowledge to classify soils. Arid Lands Newsletter 30, $19-28$.

Terassi, P.M.B., Silveira, H., \& Bonifácio, C.M. (2014). Variação da estabilidade de agregados e as suas relações com a vulnerabilidade dos solos ao longo de uma vertente na região noroeste do Paraná. Bol. Geogr., 32(1):166-176. https:// doi.org/10.4025/bolgeogr.v32i1.18169.

Tupinambá, M., Heilbron, M., Duarte, B.P., Nogueira, J.R., Valladares, C., Almeida, J., ..., , \& Ludka, I. (2007). Geologia da Faixa Ribeira Setentrional: Estado da Arte e Conexões com a Faixa Araçuaí. Geonomos, 15(1):67-79.

Turetta, A.P.D., Castro, S.S., \& Polidoro, J.C. (2017). Solos, sustentabilidade e provisão de serviços ecossistêmicos. Boletim Informativo da SBCS, 26-30. Retirado de https://www.alice.cnptia.embrapa.br/ bitstream/doc/1080522/1/2017040.pdf.

Vale Jr., J.F., Schaefer, C.E.G.R., \& Costa, J.A.V. (2007). Etnopedologia e transferência de conhecimento: diálogos entre os saberes indígena e técnico na terra indígena Malacacheta, Roraima. Revista Brasileira de Ciência do Solo, 31:403-412. http:/ / dx.doi.org/10.1590/S0100-06832007000200023. 
Vezzani, F.M. (2015). Solos e os Serviços Ecossistêmicos. Revista Brasileira de Geografia Física, 8:673-684. https://doi.org/10.26848/rbgf.v8.0.p673-684.

Vezzani, F.M., \& Mielniczuk, J. (2011). Agregação e estoque de carbono em Argissolo submetido a diferentes práticas de manejo agrícola. Revista Brasileira de Ciência do Solo, 35:213-223. https:/ / doi.org/10.1590/S010006832011000100020.

Wang, K., Zhang, C., Chen, H., Yue, Y., Zhang, W., Zhang, M., Qi, X., \& Fu, Z. (2019). Karst landscapes of China: patterns, ecosystem processes and services. Landscape Ecol, 34:2743-2763.

Yoder, R.E. (1936). A direct method of aggregate analysis of soils and a study of the physical nature of erosion losses. Journal American Society Agronomy,28:337- 351.

Zinn, Y.L., Lal, R., \& Resck, D.V.S. (2011). Eucalypt plantation effects on organic carbon and aggregation of three different-textured soils in Brazil. Soil Research, Collingwood, 49(7):614-624. 
Quadro 2: Síntese dos serviços ecossistêmicos relacionados aos solos do Sítio PROMATA.

\begin{tabular}{|c|c|c|c|c|}
\hline \multicolumn{5}{|l|}{ VALOR INTRÍNSECO } \\
\hline \multicolumn{5}{|l|}{ SERVIÇOS ECOSSISTÊMICOS } \\
\hline REGULAÇÃO & PROVISÃO & SUPORTE & CULTURAL & CONHECIMENTO \\
\hline $\begin{array}{l}\text { Os solos analisados no Sítio } \\
\text { PROMATA apresentam } \\
\text { características físico-químicas } \\
\text { que podem contribuir para seu } \\
\text { funcionamento adequado e, } \\
\text { possivelmente, sua atuação na } \\
\text { regulação de processos terrestres. } \\
\text { Coletas de amostras de solos } \\
\text { volumétricas foram importantes } \\
\text { para verificar a qualidade do solo, } \\
\text { e demonstraram que os solos } \\
\text { possuem: } \\
\text { Elevada porcentagem de matéria } \\
\text { orgânica, média } \geq 3 \% \text {; } \\
\text { pH ácido (4,1 - 4,4), em virtude } \\
\text { da pluviosidade e teor de matéria } \\
\text { orgânica elevados; } \\
\text { Presença de vários organismos, } \\
\text { como minhocas e formigas; } \\
\text { Porcentagem mais elevada da fração } \\
\text { areia; } \\
\text { Baixa densidade do solo (0,6g/ } \mathrm{cm}^{3} \text { - } \\
\left.0,7 \mathrm{~g} / \mathrm{cm}^{3}\right) \text {; } \\
\text { Alta porosidade total ( }>70 \%) ; \\
\text { Estável em água, com elevados } \\
\text { índices de estabilidade de agregados } \\
\text { (> } 74 \% \text { ). }\end{array}$ & $\begin{array}{l}\text { A explotação mineral para } \\
\text { a construção civil pode ser } \\
\text { considerada um serviço } \\
\text { ecossistêmico de provisão, } \\
\text { proporcionado pelos solos, } \\
\text { relacionado ao seu valor } \\
\text { monetário para o homem. } \\
\text { Figura 1. Explotação } \\
\text { mineral em Ubatuba/SP. }\end{array}$ & $\begin{array}{l}\text { Importante recurso para o } \\
\text { desenvolvimento de atividades } \\
\text { humanas, como a agricultura e } \\
\text { moradia. A expansão da cultura } \\
\text { de bananas foi possível em } \\
\text { virtude das condições naturais da } \\
\text { área, como clima quente e úmido } \\
\text { e solos com propriedades físicas e } \\
\text { químicas adequadas. } \\
\text { Figura 2. Resquícios da plantação } \\
\text { de bananas na área de estudo. } \\
\text { Fot } \\
\text { Foto: Aline M. Rodrigues (2017). } \\
\text { As habitações caiçaras eram } \\
\text { moldadas com materiais } \\
\text { encontrados na natureza, como } \\
\text { madeira e solo, basicamente, o } \\
\text { qual era utilizado para erguer as } \\
\text { paredes. } \\
\text { Figura 3. Estrutura de uma } \\
\text { casa de pau a pique no Sítio } \\
\text { PROMATA. } \\
\text { Foto Aline M. Rodrigues (2018). }\end{array}$ & $\begin{array}{l}\text { As habitações tipicamente caiçaras, } \\
\text { de pau a pique, também estão } \\
\text { relacionadas ao viés cultural, } \\
\text { representando um modo de vida } \\
\text { baseado no uso dos recursos } \\
\text { naturais, que passaram a } \\
\text { constituir a base da identidade } \\
\text { de uma comunidade. As formas } \\
\text { de uso e apropriação dos solos } \\
\text { correspondem a um conhecimento } \\
\text { transmitido de geração em geração } \\
\text { e caracterizam a riqueza cultural } \\
\text { dos Caiçaras e sua relação com este } \\
\text { elemento abiótico. } \\
\text { Figura 4. Museu Caiçara, } \\
\text { Ubatuba/SP. } \\
\text { (XW" }\end{array}$ & $\begin{array}{l}\text { No Sítio PROMATA, } \\
\text { pesquisas em solos estão sendo } \\
\text { realizadas com o objetivo de } \\
\text { informar a população quanto } \\
\text { a importância deste elemento } \\
\text { abiótico, visando o fomento da } \\
\text { educação, bem como a possível } \\
\text { geração de empregos, a partir } \\
\text { do uso dos recursos abióticos } \\
\text { adequadamente, em uma área } \\
\text { com vocação turística. } \\
\text { Figura 5. Realização de } \\
\text { atividade educacional. Painel } \\
\text { interpretativo implantado na } \\
\text { área de estudo. }\end{array}$ \\
\hline
\end{tabular}

Data de submissão: 12 / maio/2020

Data de aceite: 19 /out./2020 